EG'G-EP-10500

DE93 007224

\title{
A Comparative Analysis of Alternative Fuels for the INEL Vehicle, Fleet
}

\author{
Stephen Priebe \\ Wayne Boyer \\ Karren Church
}

Published November 1992

\begin{abstract}
Idaho National Engineering Laboratory
EG\&G Idaho, Inc.

Idaho Falls, Idaho $\mathbf{8 3 4 1 5}$
\end{abstract}

Prepared for the

U.S. Department of Energy

Assistant Secretary for Conservation and Renewable Energy

Under DOE Idaho Field Office

Contract DE-AC07-76ID01570

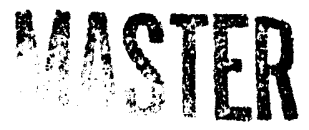

BISTRIBUTION OF THS OOCUMENT IS UNUMITE 


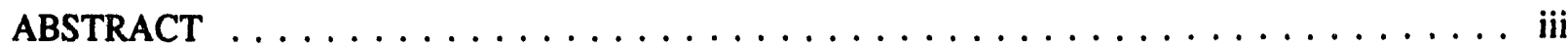

EXECUTIVE SUMMARY $\ldots \ldots \ldots \ldots \ldots \ldots \ldots \ldots \ldots \ldots$

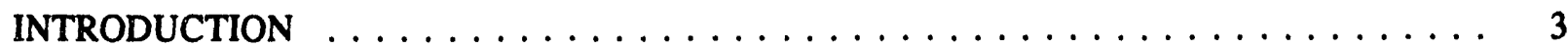

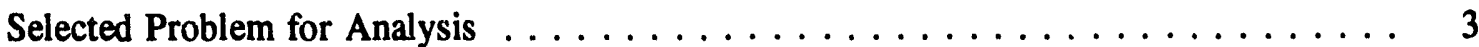

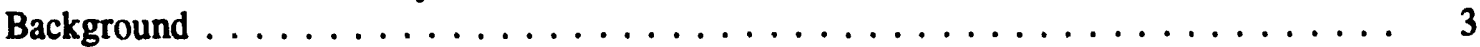

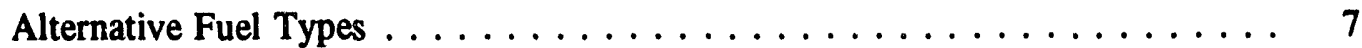

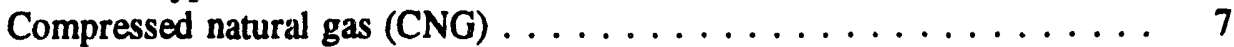

Liquefied natural gas (LNG) $\ldots \ldots \ldots \ldots \ldots \ldots$

Liquefied petroleum gases (LPG) $\ldots \ldots \ldots \ldots \ldots \ldots$

Methanol/gasoline blend (M85) $\ldots \ldots \ldots \ldots \ldots \ldots \ldots$

Ethanol/gasoline blend (E85) $\ldots \ldots \ldots \ldots \ldots \ldots \ldots \ldots \ldots$

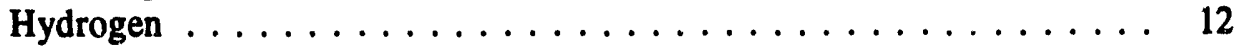

Electric vehicle $\ldots \ldots \ldots \ldots \ldots \ldots \ldots \ldots \ldots \ldots$

Considerations for Converting to Alternative Fuels $\ldots \ldots \ldots \ldots \ldots \ldots$

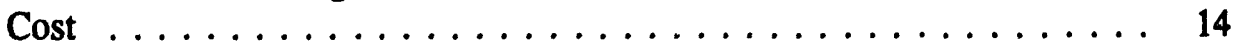

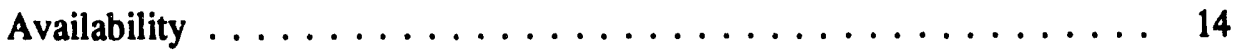

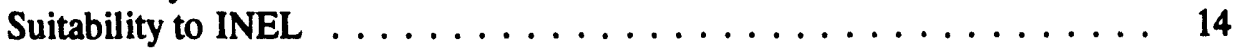

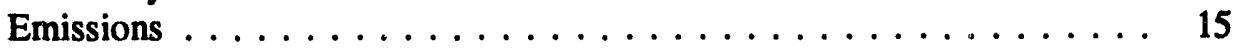

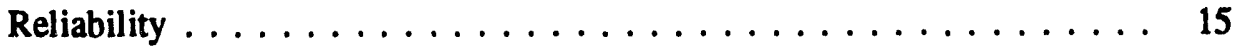

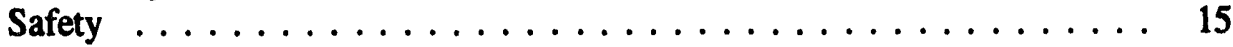

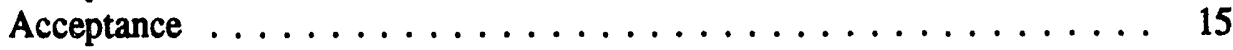

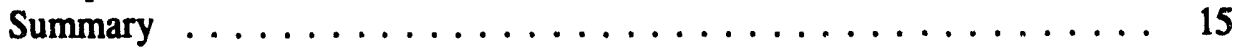

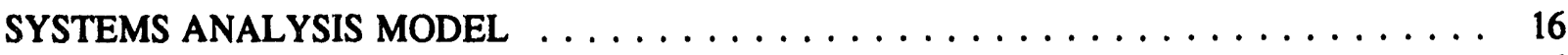

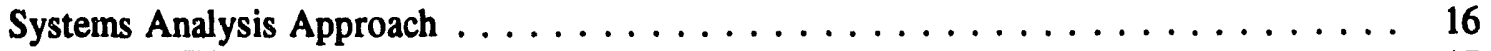

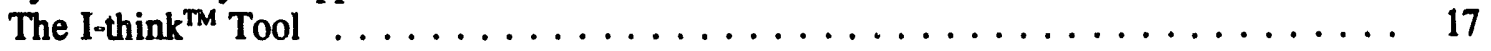

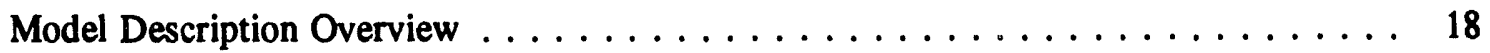

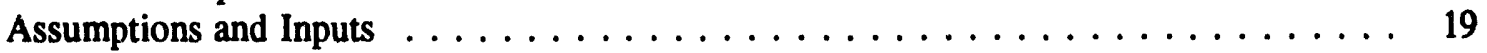

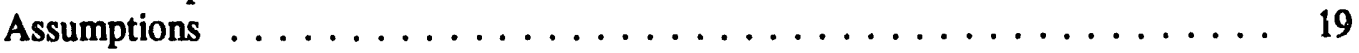

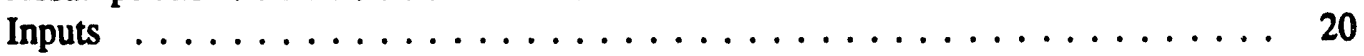

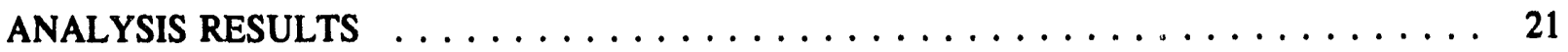

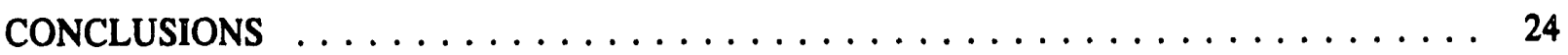

Appendix A Detailed Model Description $\ldots \ldots \ldots \ldots \ldots \ldots \ldots \ldots \ldots \ldots \ldots \ldots \ldots$

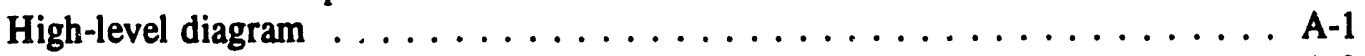

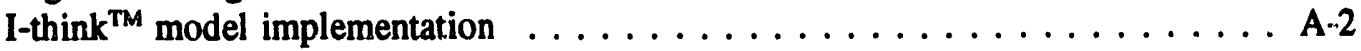

Control Panels . . . . . . . . . . . . . . . . A

Vehicle Flow Model $\ldots \ldots \ldots \ldots \ldots \ldots \ldots \ldots$ A-2

Cost Flow Model . . . . . . . . . . . . . . . A-2

Introduction Process Model $\ldots \ldots \ldots \ldots \ldots \ldots \ldots \ldots$ A-2

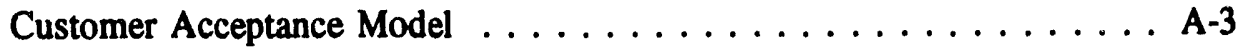

Emissions and Fuel Flow Model $\ldots \ldots \ldots \ldots \ldots \ldots \ldots$ A-3

Appendix B Model Diagrams \& Equations $\ldots \ldots \ldots \ldots \ldots \ldots \ldots \ldots \ldots \ldots \ldots$ 
Appendix C Input Data $\ldots \ldots \ldots \ldots \ldots \ldots \ldots \ldots \ldots \ldots \ldots \ldots \ldots \ldots \ldots$

REFERENCES $\ldots \ldots \ldots \ldots \ldots \ldots \ldots \ldots \ldots \ldots \ldots \ldots \ldots \ldots \ldots$ 


\begin{abstract}
This report summarizes the results of a comparative systems analysis of various alternative fuels for use in the buses, mid-size vehicles, and automobiles that make up the vehicle fleet at the Idaho National Engineering Laboratory (INEL). The study was performed as part of the Laboratory Directed Research and Development (LDRD) Program for EG\&G Idaho, Inc. Regulations will require the INEL to reduce total gasoline and diesel fuel use $10 \%$ by 1995 compared with 1991 levels, and will require that $50 \%$ of all new vehicles be fueled by some type of alternative fuel by 1998 . A model was developed to analyze how these goals could be achieved, and what the cost would be to implement the goals.
\end{abstract}




\section{A Comparative Analysis of Alternative Fuels for the INEL Vehicle Fleet}

\section{EXECUTIVE SUMMARY}

Beginning in March 1992, a Laboratory Directed Research and Development (LDRD) Program was undertaken to develop and prove the potential of simulation software to analyze operating energy issues at the INEL. As a test problem for the LDRD, a study was undertaken of alternative fuels to replace gasoline and diesel currently used in the INEL vehicle fleet. On April 17, 1991, Executive Order 12759 was signed ordering all federal agencies to develop and implement a plan to meet the energy management goals of the National Energy Conservation Policy Act and the Alternative Motor Fuels Act. Included in those goals are:

1. Section 10: By 1995 reduce total Federal fleet (including INEL) usage of gasoline and diesel fuels by $10 \%$ compared with 1991 levels.

2. Section 11: Provides a schedule for purchase of new alternatively fueled vehicles (AFVs) during the period 1993 to 1998.

This study is intended to help the INEL fleet management staff who must develop a plan to meet those goals to reduce overall gasoline and diesel use, and to substitute alternatively fueled vehicles into the fleet.

A relatively recent software package called I-think ${ }^{T M}$ from High Performance Systems, Inc. was used to model the fuel use and the impact of alternative fuels on the cost associated with operating the INEL vehicle fleet. The model was applied to all vehicle types currently in use at INEL: cars, midsize vehicles (including trucks), and buses. A number of aspects relating to the substitution of alternative fuels were considered:

- Fuel use

- Costs - Capital: new vehicles, conversion of existing vehicles, and implementing the infrastructure necessary to support alternative fuels. Operating: fuel, maintenance, insurance, training, etc.

- Emissions - $\mathrm{NO}_{\mathrm{x}}, \mathrm{CO}$, and nonmethane hydrocarbons (NMHC)

- Reliability/customer acceptance

The potential alternative fuels initially considered were:

- Compressed natural gas (CNG)

- Liquefied natural gas (LNG)

- Methanol/gasoline blend (M85) 
- Ethanol/gasoline blend (E85)

- Liquefied petroleum gas (LPG)

- Hydrogen

- Electric vehicle

The electric vehicle is not strictly an alternative fuel, but does represent an alternative to gasoline and/or diesel fuel use. Of the fuels studied, hydrogen and electric vehicle were eliminated, because the technology is not developed sufficiently to meet the goals. The model was developed with input from numerous sources including INEL fleet management, tests of AFVs performed in other areas, and studies of emissions and safety performed by various government and private entities.

The analysis was performed to cover a period of 20 years, which would allow full implementation of any alternative vehicle plan. The scenario chosen for study was one that would meet the two primary goals summarized above. It was assumed that the vehicle usage would not change, but that there would be a $10 \%$ improvement in gasoline vehicle efficiency by 1995 . This implies that the remainder of the fuel reduction goal would have to be met through the use of alternative fuels.

Results show that, by itself, the AFV introduction schedule in the guidelines of Section 11 of Executive Order 12759 will not be sufficient to meet the $10 \%$ fuel use reduction goal by 1995 . Either the introduction of AFVs will need to be accelerated, or the average number of miles per gasoline/diesel vehicle will have to be reduced.

A primary result desired from the analysis was a determination of the incremental capital and operating costs to implement the fuel substitution plan to meet the mandates. Incremental cost is the cost above and beyond the cost for the gasoline and diesel fueled fleet. There are two parts of the cost: a one-time cost of the infrastructure, and the ongoing cost for purchase of new vehicles and operation of the INEL fleet as a whole. The infrastructure cost, assumed to occur in 1993, ranges from about $\$ 600,000$ for LNG to $\$ 2,600,000$ for E85. In 1994, the first year of implementation, the annual costs are very similar at about $\$ 100,000$ for all the alternative fuels, because the number of AFVs is small. However, by 1998 , when $50 \%$ of all newly purchased vehicles are to be alternatively fueled, the incremental annual cost ranges from about $\$ 250,000$ for LPG to $\$ 600,000$ for E85. At the end of the 20 year analysis period, the range has widened from near zero for LNG to $\$ 1,500,000$ for E85.

With the considerable uncertainty in available data for all AFVs, it is really not possible to specify a single alternative fuel as the best. However, results of this study showed that LNG, CNG, and LPG appear to be the most cost effective alternative fuels for the INEL fleet. Because the INEL has had poor experience with LPG in past tests, and LPG will likely have limited availability over the long term, LPG is not recommended as a long-term solution. Therefore a natural gas fuel will likely be the alternative fuel of choice. Because the technology for CNG is more advanced than for LNG, the first AFVs should probably be CNG with conversion to LNG as the technology becomes developed. As more data become available, the model can be used to refine and update the study. 


\section{INTRODUCTION}

\section{Selected Problem for Analysis}

As part of the Laboratory Directed Research and Development (LDRD) Program, a study was undertaken to evaluate the potential for using recent commercially-available computer software to analyze various energy conservation projects at the INEL. The objective of the project was to select one or more site specific energy issues of concern to the Power Management Group and compare alternatives for energy use and cost using the available software. The anticipated benefits of the project were to include:

- Acquiring experience and tools for integrated analysis.

- Acquire experience using state-of-the-art modeling tools.

- Develop useful studies of INEL energy management problems.

It was determined early in the project that with the time and funding available, it would be impractical to address more than one energy management problem during the project. Therefore a single analysis was selected. The problem selected was a comparative analysis of converting the current INEL fleet from gasoline and diesel vehicles to one of several alternative fuels. The study will analyze alternative fuels with respect to four general areas:

- Fuel use,

- Cost - capital and operating,

- Emissions.

- Acceptance based on reliability, safety, and quality.

The result of the analysis is to develop a recommendation as to which alternative fuel or fuels appear show the most promise for the INEL fleet, and to estimate what the cost for implementing the plan will be. This information will then be used by the fleet management group to choose a fuel for implementation.

\section{Background}

The United States and Canada are estimated to contain only 4 percent of the world's proven crude oil reserves. Conversely, the Middle East oil reserves comprise 70 percent of the world supply; the six OPEC countries (Iraq, Iran, Kuwait, Saudi Arabia, UAE, and Venezuela) control approximately 68 percent of the world's oil reserves, exceeding 600 billion barrels ${ }^{1}$. As a result, the United States must import a significant amount of crude oil. Approximately 28 percent, or 21.3 quadrillion Btu (quads), of the nation's fuel supply must support transportation activities. Therefore, a reduction in the use of transportation fuels derived from petroleum could significantly reduce the U.S. dependance on foreign crude oil, and reduce the balance of trade deficit. Policy issues and recent events in the Middle East have reinforced this need. 
The development of alternative fuel vehicles (AFVs) in the United States was instigated in the early 1970s by the high cost of gasoline. With escalating gasoline prices and increasing demand, a national effort to research alternative fuels was begun. The emphasis was to develop alternatives which would reduce gasoline fuel consumption and, therefore, dependance on foreign oil. As oil prices fell in the late 1980s, this effort was largely abandoned.

To better understand the future of AFVs and what driving forces might encourage their further development and introduction, a conference was held by three separate panels of automotive industry executives, directors, managers, and engineers who are experts in the area of automotive technology, materials, and marketing. These selected individuals have established records in the transportation sector and strategic insight on important industry trends ${ }^{2}$.

There, is, of course, an industry bias in the results of the conference, but the trends can be considered an indication of the future for AFVs. Therefore, the following statements describe the direction which industry believes the alternative fuel market is headed.

- Alternative fuel use is expected to increase, driven by environmental concerns and the Clean Air Act of 1990 Amendments. There is no incentive for alternative fuels if gasoline is inexpensive.

- No alternative fuel can compete with gasoline economically. Alternative fuel use will be increased by legislative activities and will not be able to make a significant market penetration unless the government artificially lowers the cost of alternative fuels relative to gasoline.

- Production of AFVs will depend on legislated corporate average fuel economy (CAFE) credit incentives to manufacturers, energy policy, and clean air legislation.

- Early emphasis is on natural gas, which could become the major alternative.

- Propane will not be a new vehicle option; it will remain only as aftermarket conversions.

- Electric battery technology will be practical by 2000 .

- Due to economic factors, the only method to force the development and consumption of alternative fuels involve AFV incentives and gasoline disincentives

- Hydrogen storage, efficiency, and safety problems are expected to be solved in the 1990 s.

- Alternative fuels activity will be defined by California and Texas.

- The infrastructure required for flexible fuels is the simplest to develop.

- While trucks, especially those in fleets, will increase their use of natural gas and propane, private passenger cars will not make significant use of these fuels.

The conclusions of the conference are important in understanding the future of alternative fuels. Legislative incentives are critical to the development of AFV, especially with the expected decline in oil prices. Research breakthroughs will be essential to achieving an active alternatively fueled fleet, with natural gas expected to be the fuel of choice. Ultimately, though, electric vehicles and biomass systems 
could dominate the market. This technology is developing and many operating parameters have not been determined. Assuming that the emphasis on research continues, many of the technical problems associated with alternative fuels will be resolved by the end of the decade, defining the path of $\mathrm{AFV}^{2}$.

The challenge of this study is to evaluate the requirements of the INEL and determine the correct alternative fuel to be developed.

\section{Regulatory Issues}

The requirement for reduced vehicle emissions has motivated a renewed interest in alternative fuels, shifting the emphasis to clean burning fuels. The Alternative Motor Fuels Act of 1988 (Public Law 100-494, AMFA), the National Energy Conservation Policy Act of 1988, and the Clean Air Act of 1990 Amendments (CAAA) have established aggressive national goals for both mobile (automotive) and stationary sources of pollutants ${ }^{3}$. The six major pollutants effecting urban areas are carbon monoxide (CO), nonmethane hydrocarbons (NMHC), nitrogen oxides $\left(\mathrm{NO}_{\mathrm{x}}\right)$, sulfur oxides, lead, and particulate matter. Under the CAAA, standards have been established for vehicles affecting emissions of NMHC, $\mathrm{CO}, \mathrm{NO}_{\mathrm{x}}$, and particulate matter. These standards will apply to all AFVs, regardless of fuel type. The CAAA also identifies acceptable "clean fuels", which include natural gas, ethanol, methanol, propane, electricity, reformulated gasoline, and any additional fuel that reduces tailpipe emissions.

As an example of how these regulations are being implemented at the state level, the State of California has established a clean-fuels program, which is axpected to be adopted by the nation ${ }^{4}$. These regulations require the use of reformulated gasoline, heated catalysts, and heated fuel-preparation systems. Most importantly, vehicle manufacturers will be required to develop and market AFVs. Beginning in $1998,2 \%$ of the vehicles sold must be zero-emission vehicles (ZEVs), increasing to 10 percent by $2001^{4}$. In addition to reducing emissions, the potential impact on national oil imports will be great, displacing nearly 50,000 barrels per day by $2010^{4}$.

In 1991, Executive Order 12759 was signed, directing that a plan be developed and implemented for all Federal agencies to meet the standards established in these laws. Section 10 of Executive Order 12759 states that by 1995 , total gasoline and diesel use in vehicles must be reduced by $10 \%$ from the 1991 levels. Section 11 of Executive Order 12759 sets out a timetable for converting new vehicle purchases to AFVs. That timetable is as follows:

$\begin{array}{cc}\text { Year } & \begin{array}{c}\% \text { of New Vehicles } \\ \text { to be Alternative Fuel }\end{array} \\ & \\ 1993 & 10 \\ 1994 & 15 \\ 1995 & 20 \\ 1996 & 25 \\ 1997 & 33 \\ 1998 & 50\end{array}$

INEL Vehicle Fleet

The EG\&G Fleet Management unit of EG\&G Idaho,Inc. is chartered to administer the pool of vehicles owned by the U.S. Department of Energy, Idaho Field Office. The fleet manager monitors contractor 
compliance with property management and federal property management regulations. The INEL has two primary vehicle pools, separated by approximately 50 miles, and seven satellite pools located throughout the site. Administration of contractor requirements and regular maintenance of the vehicles are also responsibilities of fleet management. Each contractor is responsible for managing and distributing fleet vehicles within its company and ensuring compliance with federal property management regulations.

Table 1 shows the composition of the vehicle fleet at the INEL. It contains a total of 879 vehicles consisting of 136 diesel-fueled buses, 601 gasoline-fueled mid-size vehicles including light-duty trucks, and 158 gasoline-fueled cars, and consumes 966,000 gallons of diesel and 544,000 gallons of gasoline. Buses are used primarily for travel to and from the site, while other vehicles are used primarily for shorter trips either at the site or in town. Other vehicles, such as medium and heavy duty trucks, are exempt from the guidelines. It is expected that these numbers will remain relatively constant for the foreseeable future.

Table 1. Composition of INEL Vehicle Fleet

\begin{tabular}{lcccc}
$\begin{array}{l}\text { Vehicle } \\
\text { Type }\end{array}$ & $\begin{array}{l}\text { Number of } \\
\text { Vehicles }\end{array}$ & $\begin{array}{l}\text { Miles } \\
\text { Driven" }\end{array}$ & $\begin{array}{c}\text { Fuei } \\
\text { Coisumed }\end{array}$ & $\begin{array}{c}\text { Miles per } \\
\text { Gallon }\end{array}$ \\
\hline Buses & 136 & $5,700,000$ & 960,000 & 5.9 \\
Cars & 158 & $2,734,000$ & 106,000 & 25.8 \\
& & $5,725,000$ & 438,000 & 13.1 \\
Mid-size \& trucks 601 & & & \\
\hline a. Base year-1991 & & & & \\
\hline
\end{tabular}




\section{Alternative Fuel Types}

AFVs can be operated, and therefore separated, into three categories: vehicles that operate exclusively on a single fuel, vehicles that operate on specific fuel blends, and vehicles that operate on flexible fuel mixtures. Vehicles that operate on a single fuel are considered dedicated vehicles, with engines designed specifically for one fuel. These vehicles can be optimized to ensure peak engine performance. Engines operating on blends are designed for given combinations of an alternative fuel and gasoline. These blends generally have higher emissions than the pure fuel, because of the combustion of gasoline. Flexible fuel vehicles (FFVs) operate using two separate fuels, generally gasoline and an alternative fuel, allowing for easy transition from the gasoline to the alternative fuel tank. These systems are especially advantageous for extended range vehicles, because of the additional tank. Each category has specific advantages that must be considered in determining an alternative fuel program.

This study addresses those alternative fuels that can best be applied to the INEL without compromising facility operations. Alternative fuels analyzed in this study were methanol/gasoline blend (M-85), ethanol/gasoline blend (E-85), compressed natural gas (CNG), liquefied natural gas (LNG), liquefied petroleum gas (LPG), electricity, and hydrogen. These fuels were evaluated using a selection criteria to determine the most suitable transportation fuel. Considerations include miles traveled per day, maintenance requirements, tailpipe emissions, local fuel supply, and financial demands. The alternative fuel selected must propel the INEL into the next decade, achieving aggressive goals. A brief description of each is given below. Table 1 shows a comparison of the energy density and cost for each of the alternative fuels, and the expect range of a vehicle. It should be noted that the range of any of the alternative fuels can be increased by increasing the fuel capacity. However, this will likely cause a reduction in the storage capacity of the vehicle.

Table 1. Alternative fuel comparison.

\begin{tabular}{|c|c|c|c|c|}
\hline Fuel type & Form & $\begin{array}{l}\text { Energy Density } \\
\text { (Btu/gal) }\end{array}$ & $\begin{array}{l}\text { Vehicle Range } \\
\text { (Miles/tank) }\end{array}$ & $\begin{array}{c}\text { Cost } \\
\text { (\$/equiv gal) }\end{array}$ \\
\hline Gasoline & Liquid & 114,000 & 300 & 1.18 \\
\hline Diesel & Liquid & 83,800 & & 1.35 \\
\hline CNG & Gaseous & $21,800-32,700^{b}$ & 100 & 0.60 \\
\hline LNG & Liquid & 83,700 & 300 & 0.62 \\
\hline LPG & Liquid & 91,600 & 240 & 0.98 \\
\hline M85 & Liquid & 57,000 & 200 & 1.04 \\
\hline E85 & Liquid & 76,000 & 200 & 1.58 \\
\hline Hydrogen & a & $13,000^{c}$ & $<100$ & 2.90 \\
\hline Electric Vehicle & N/A & $\mathbf{N} / \mathbf{A}$ & 100 & 1.21 \\
\hline
\end{tabular}

a. Hydrogen may be gaseous, cryogenic liquid, or combined in a metal hydride matrix.

b. Depends upon pressure of CNG in tank - 2400 to $3600 \mathrm{psi}$

c. Energy density for metal hydride. For compressed gas, energy density is about $50,000 \mathrm{Btu} / \mathrm{gal}$.

Compressed natural gas (CNG). Natural gas is generally found in natural gas reserves, but it could be produced from coal. The composition of natural gas varies throughout the country, depending 
on original gas composition and processing. Pipeline quality natural gas is composed of several different gases with methane typically accounting for $85 \%$ to $99 \%$. Other constituents include ethane, propane, some butanes, trace amounts of other hydrocarbons, nitrogen, helium, carbon dioxide, and trace amounts of hydrogen sulfide, water, and odorants. Large amounts of non-methane hydrocarbons are typically added to methane to enrich the fuel mixture leading to a reduced octane number, increased hydrocarbon emissions, deterioration of the engine, and engine knocks.

Current natural gas vehicles are primarily light duty, gasoline fueled vehicles converted to dual fuel capability. Cost of converting a light duty gasoline vehicle to dual-fuel capabilities with CNG is approximately $\$ 2,500$ to $\$ 3,500$ per vehicle. Some limited conversions of diesel engines to CNG have been done, but they are not generally available. New vehicle warranties remain valid after vehicle conversion provided the cause of part failure is not due to the conversion. Compressed natural gas (CNG) is stored in cylinders at 2400 to $3600 \mathrm{psi}$, and then released to the engine through a pressure valve. CNG cylinder corrosion can occur from the formation of sulfuric acid from hydrogen sulfide and water vapor in the natural gas supply.

Basically, refueling stations may be located at gasoline stations though modifications are required for natural gas tanks. Refueling time for CNG may be arranged as either slow-fill or fast-fill. The slow-fill system use over-night refueling and costs are significantly less than fast-fill system. Refueling time for fast-fill system is only slightly longer than for a gasoline system, and so are likely to be the system of choice?

Natural gas is lighter than air with a specific g:avity of 0.56 to 0.62 relative to air, depending on gas composition. Being a gas, CNG disperses readily, and cannot accumulate in pools on the ground or beneath a leak. Odorants are added to allow for detection before dangerous concentrations are achieved. Natural gas is a non-toxic gas, but can cause suffocation ${ }^{8}$.

The autoignition temperature for natural gas at atmospheric pressure is $1004^{\circ} \mathrm{F}$ compared to $442^{\circ} \mathrm{F}$ to $880^{\circ} \mathrm{F}$ for gasoline and $500^{\circ} \mathrm{F}$ for diesel. The concentration range where CNG is flammable in air is $5.3 \%$ to $15 \%$ for natural gas, compared with $1.4 \%$ to $7.6 \%$ for gasoline. Ignition within the storage cylinder is not possible due to the lack of oxygen in CNG cylinders. Natural gas has a research octane rating of about 130 compared with 91 for gasoline. At $1000 \mathrm{Btu} / \mathrm{ft}^{3}, 1 \mathrm{ft}^{3}$ of CNG has the energy equivalent of 1.4 to 2.1 gallons of gasoline or 1.9 to 2.9 gallons of diesel'.

Performance and driveabilty of methane vehicles are different from GFVs. Theoretically, conversion of a gasoline engine to natural gas reduces power output by $10 \%$. In practice, power loss is usually greater than $10 \%$, but does not exceed $17 \%$. The average driver is insensitive to power losses of $10 \%$ to $15 \%$ under normal conditions. Tuning ignition timing and air/fuel mixture can optimize performance, fuel economy, and emissions. The CNG fuel cylinder range is typically 80 to 100 miles. With duel fuel capability, this distance is in addition to the gasoline tank range. At low ambient temperatures, natural gas cold start ability is better than gasoline ${ }^{10,11}$.

Because CNG is a vapor, CNG vehicles have no evaporative emissions as such, but they do have fugitive emissions as residual natural gas leaks from the fuel system when not operating. Emissions of concern are carbon monoxide (significantly lower than gasoline), nitrogen oxides (may be slightly higher than gasoline), and total hydrocarbons (typically $40 \%$ to $60 \%$ lower than gasoline). EPA emission standards for methane vehicles are expected to be published in late 1992. Also, compliance with the 1990 
Clear Air Act Amendments, the California Air Resource Board (CARB), and the State of Colorado clean air standards will be required by $1993^{12,13}$.

Liquefied natural gas (LNG). LNG is essentially pure methane that has been liquified at a temperature of $-260^{\circ} \mathrm{F}$ and 10 to $20 \mathrm{psig}$. As with CNG, LNG should be widely available, if the liquefaction facilities are built. The fuel transport system could be handled two ways: (a) natural gas pipelines to local liquefaction facilities/distributors, or (b) centralized liquefaction facilities with transport of LNG to local stations. The choice between these two will depend upon the volume and economics cf LNG handled by local stations, and the development of small-scale liquefaction systems, ${ }^{5}$.

CNG and LNG are very similar in performance and emissions. The only significant difference is in the fuel tank and filling system. The performance of LNG vehicles is identical to CNG, because the fuel is vaporized before reaching the engine. As with CNG, LNG has been used primarily in light duty, GFVs converted to dual fuel capability. Cost for converting a light duty gasoline vehicle to dual-fuel capabilities with LNü is comparable with CNG at approximately $\$ 2,500$ to $\$ 3,500$ per vehicle. The engine conversion is the same as for CNG, but the fuel delivery system will be different, with two options currently being considered: (a) high pressure (3000 psi) and (b) low pressure. The high pressure system does not require cryogenic storage and is further developed than the low pressure system that requires $-20^{\circ} \mathrm{F}$ fuel storage. To bridge the gap until LNG development reaches a satisfactory point, vehicles could be first converted to CNG. Then, when the fuel system is fully developed, the final conversion to LNG could be completed. Because LNG has a greater fuel density, vehicles have a range of about 300 miles. As with CNG, little work has been done to convert diesel engines to LNG. One gallon of LNG has the energy equivalent of about 0.75 gallons of gasoline or 1.0 gallon of diesel The fuel tank filling system, which must be able to handle the cryogenic liquid also requires some development ${ }^{6,8}$.

LNG is stored in tanks at 10 to 30 psig and $-260^{\circ} \mathrm{F}$. Severe frostbite may occur from contact with LNG or associated cold components. LNG vapors cannot be detected by smell. The severe low temperatures with LNG may alier the strength characteristics of many common materials located in the fuel chamber ${ }^{14}$.

Liquefied petroleum gases (LPG). LPG consists of one or more liquified hydrocarbon gases including propane, butane, and pentane, but propane is the primary constituent of interest as a transportation fuel. LPG is produced in conjunction with both natural gas (55\%) and crude oil (45\%). It is currently used on a limited basis as fuel for domestic heating and cooking, and to some extent as a motor fuel. The distribution network is extensive, but in somewhat limited quantities. With its primary source being as a minor constituent of natural gas production, the fuel supply could be limited. Propane could be produced from other sources, but the cost would increase significantly. Because LPG is odorless, an odorant is added to fuel grade LPG to aid in the detection of leaks. Fuel grade propane is currently available in many truck stops. Refinery produced LPG generally contains greater amounts of propylene and other low octane components, however specifications used for standard propane (HDS) ensures consistency ${ }^{15}$.

LPG vehicles are primarily retrofitted GFVs with pick-up trucks and medium duty trucks comprising the greatest number of vehicles. Several state and local vehicle fleets have been converted to LPG at least on a trial basis. However, the INEL has experienced relatively low reliability with LPG vehicles. Little development has been done toward conversion of diesel fueled vehicles to LPG. LPG is stored as liquid form under pressure in cylinders located in the truck bed or trunk of an automobile. Gasoline or diesel 
vehicle conversion to LPG costs approximately $\$ 1,500$ and involves the installation of a fuel storage cylinder mounted on the frame and several engine compartment modifications. Propane has a research octane rating of about 110 to 120 , butane 105 to 110 , compared with 91 for gasoline $e^{6.16}$.

Refueling stations may be located on the same sites as gasoline stations though modifications are required for propane. Refueling time for LPG vehicles is slightly longer than for gasoline systems. Propane has a boiling point of $-44^{\circ} \mathrm{F}$ and therefore rapidly boils and vaporizes when exposed to atmospheric temperatures and pressures ${ }^{6}$.

LPG vapors are heavier than air with a specific gravity of 1.5 relative to air (air $=1$ ) at $65^{\circ} \mathrm{F}$. Initial releases of LPG expand from a liquid state to a gas state with a volume increase of 270 times. Norants are added to allow for detection before dangerous concentrations are achieved. Explosions of LPG tanks may occur when vaporization is higher than can be relieved through the pressure relief system. The autoignition temperature for propane gas at atmospheric pressure is $855^{\circ} \mathrm{F}$ compared to $442^{\circ} \mathrm{F}$ to $880^{\circ} \mathrm{F}$ for gasoline and $500^{\circ} \mathrm{F}$ for diesel. The range of flammability in air is $2.4 \%$ to $9.6 \%$ for propane gas, compared with $1.4 \%$ to $7.6 \%$ for gasoline ${ }^{12}$.

Propane is a non-toxic gas; no harmful long-term effects from repeated exposure to propane vapors has been reported, although high concentrations of LPG causes asphyxiation. Also, severs frostbite may occur from contact with LPG or associated cold components ${ }^{12}$.

Performance and driveabilty of propane vehicles are essentially the same as with GFVs. Tuning ignition timing and air/fuel mixture can optimize performance, fuel economy, or emissions. Using the same volume LPG tanks as conventional tanks, LPG vehicle range is 10 to $20 \%$ less than gasoline vehicle range. Increasing the tank size can compensate for any distance loss. At low ambient temperatures, propane cold start ability is better than gasoline. However, under extremely cold iemperatures, when vapor pressure in the storage tank is low, cold start difficulties have been reported as a result of an insufficient vapor pressure difference between the fuel tank and the pressure regulator. Converted LPG vehicles have slight reductions in acceleration and maximum power speed of about 5\% compared with gasoline engines ${ }^{17}$.

LPG vehicles have no evaporative emissions under normal operating conditions. Emissions of concern are carbon monoxide (significantly lower than gasoline), nitrogen oxides (lower than gasoline), total reactive organics (lower than gasoline), and hydrocarbons (slightly higher than gasoline). EPA emission standards for propane vehicles are expected to be published in late 1992 by the Office of Control Technology. Also, compliance with the 1990 Clear Air Act Amendments, the California Air Resource Board (CARB), and the State of Colorado clean air standards will be required by $1993^{16}$.

Methanol/gasishise blend (M85). Most methanol is produced from a mixture of carbon monoxide and hydrogen, which in turn is produced from coal, air, and steam. Methanol can also be produced from natural gas or biomass, but this is an unlikely source for transportation purposes. Methanol is a significant commodity chemical in the petrochemical industry, but significant use as a fuel would require a dramatic increase in production. Current production cannot adequately supply the national transportation fuel demands. Prices range from $\$ 0.90$ to $\$ 1.10$ per equivalent gallon ${ }^{18}$.

Technically, methanol-fueled vehicles operate identically to gasoline engines and are separated into three classes; those that operate on 100 percent (neat) methanol; those that require a particular fuel mix, such as M85 (85\% methanol and $15 \%$ gasoline); and flexible fuel vehicles (FFVs) that run on fuel 
mixture ranging from M85 to $100 \%$ gasolinu. The most likely blend selected for vehicle use will likely be M85, although only $85 \%$ of the credit for the gasoline/diesel offset required by 1995 can be taken. With the reduced fuel density, ignition is difficult. Methanol is most commonly blended with gasoline (M85) to improve cold weather starts, driveability, and engine wear. Methanol corrodes, magnesium, copper, lead, zinc, and aluminum parts, in addition to some synthetic gaskets. The corrosiveness of M85 wiil require materials changes within the engine and fuel system. The effect of the corrosivity will be to increase either the conversion cost or the maintenance cost. There has been limited conversion of diesel vehicles to methanol. Difficulties with cold starts have essentially been solved with the installation of block heaters, fuel heaters, and volatility entancers. ${ }^{16,19}$

Methanol fueling stations can be located at gasoline stations, though some modifications are required for M85 tanks. The time to refuel FFVs may be slightly longer than for GFVs. Methanol vapors are slightly heavier than air and therefore vapors will tend to accumulate in the area of a spill. Methanol is miscible with water, increasing the environmental risk in the event of leakage, such as from a storage tank. ${ }^{20}$

Though not a carcinogen, methanol is toxic and all contact should be avoided including inhalation, ingestion, and skin penetration. Methanol does not accumulate in the body. However, with repeated low exposures, methanol is metabulized to produce formate. Ingestion of 3 to 4 teaspoons of methanol is toxic, 20 to 40 teaspoons is fatal. Pure methanol is both tasteless and odorless, however, fuel grade methanol has additives that allow for taste and odor detection ${ }^{18}$.

Range of flammability in air is $7.3 \%$ to $36 \%$ methanol compared with $1.4 \%$ to $7.6 \%$ for gasoline. M85 can form flammable mixtures in fuel tanks below $0^{\circ} \mathrm{F}$, at higher temperatures, the air to fuel mixture is too rich for ignition (compared with gasoline, closed fuel tanks form flammable mixtures below $-15^{\circ} \mathrm{F}$ ). Ignition hazard can be virtually eliminated with the installation of flame arresters on the fill pipe and tank vents. It is best to treat M-85 as gasoline in open air situations and as neat or pure alcohol in closed fuel tanks ${ }^{20}$.

Performance and driveabilty of alcohol vehicles is essentially the same as GFVs. Tuning the ignition timing and air/fuel mixture can optimize either performance, fuel economy, or emission. There may be a small increase in vehicle weight from larger fuel tanks used on some FFV's, thus decreasing efficiency ${ }^{20}$.

The mileage for M85 is approximately half that for gasoline (11.4 mpg versus $21.7 \mathrm{mpg}$ ), which translates into a range of about 200 miles for M85. Larger fuel tanks would increase the vehicle range, but would reduce fuel efficiency as compared with GFVs, and would reduce the vehicle storage space ${ }^{19,21}$.

Emissions of concern for methanol include aldehydes (primarily formaldehyde), carbon monoxide (lower than gasoline), nitrogen oxides (lower than gasoline), and total hydrocarbons (may be slightly higher than gasoline). EPA emission standards for methanol vehicles were published in the April 11, 1989 Federal Register. Also, compliance with the 1990 Clear Air Act Amendments is required and California's low emissions vehicle (LEV) standard is suggested ${ }^{17}$.

Ethanol/gasoline blend (E85). Most ethanol is produced by the hydration of ethylene. Ethanol can also be produced by fermentation of grain or other biomass, but despite political pressure to use the U.S. grain surplus to produce ethanol, the economics will continue to favor the classical route, which is 
less costly and gives a purer ethanol. Based upon sugar produced ethanol prices in Brazil, the cost of ethanol is expected to be $\$ 0.65$ to $\$ 0.85$ per gasoline equivalent gallon ${ }^{18}$.

Ethanol is chemically similar to methanol, therefore many of the characteristics found in methanol apply to ethanol. As with methanol, ethanol vehicles are separated into three classes; those that operate on 100 percent (neat) ethanol, fuel mixes, such as M85, and FFV. It is most likely that E85 would be the composition of choice. E85 is a blend of $85 \%$ ethanol and $15 \%$ gasoline. As with M85, the gasoline improves the octane and makes the flame visible. Again, because of the gasoline content, only $85 \%$ of the credit for the gasoline/diesel offset required by 1995 can be taken. As with M85, conversion of GFVs to E85 is relatively easy and, because E85 is less corrosive than M85, there will be fewer materials problems, so either the purchase cost or the maintenance cost will be lower. Currently, ethanol is blended with gasoline (E85) to improve cold weather starts, driveability, and engine wear. Fuel economy for E85 vehicles is about 30\% lower than for GFVs. Little development has been undertaken toward conversion of diesel vehicles to ethanol. Ethanol has been used as a gasoline additive and octane enhancer since the early 1980's, because of the significant tax incentives offered for ethanol from fermentation. Ethanol does not attack the engine nearly as much as methanol. Recently, ethanol has been seen as a good way to increase the oxygen of fuel, which is being required by various regulations ${ }^{18,20}$.

Ethanol is much less toxic than methanol, but fuel grade ethanol contains toxic additives which are harmful and/or carcinogenic. Range of flammability in air is $3.3 \%$ to $19 \%$ for ethanol, compared with $1.4 \%$ to $7.6 \%$ for gasoline. Emissions for ethanol are similar to those for methanol ${ }^{18}$.

Hydrogen. Hydrogen is a gas, and is used in large quantities in the petrochemical industry, but the large-scale distribution network required for fuel use is not available. Reforming natural gas or coal gasificacion can be used to synthesize hydrogen. Research indicates that reforming natural gas in existing underground pipelines can be used to recharge hydrogen storage tanks. Hydrogen can also be produced by the electrolysis of water. Hydrogen can be stored as a compressed gas, a cryogenic liquid, or chemically combined in a metal matrix called a metal hydride. It is also possible to use hydrogen in a fuel cell to produce electricity, thereby creating a hydrogen powered electric vehicle ${ }^{21}$.

Hydrogen is nominally a zero emissions fr 1 , providing additional benefits to traditional combustion engines. However, if one considers the emissions necessary to produce the hydrogen, then the claim for zero emissions loses some credibility. It does however, convert a mobile source to a point source, which could make control easier. Hydrogen fueled vehicles fall into three categories. The first class of vehicles are those similar to a gasoline engine, with the ability to operate on both gasoline and hydrogen. Vehicles using metal hydride comprise the second group, operating on a hydrogen cycle that releases interstitial hydrogen from the metal hydride. The final category is hydrogen fuel cells, which generate electricity through a proton exchange membrane. Hydrogen is far from a commercial application, but many test vehicles have been developed. Most hydrogen vehicles operate by a combination of the above, for instance, incorporating metal hydride storage with a fuel cell. Major technological difficulties are expected to be overcome by 2000 , but this is not sufficient to meet the mandated goals for the INEL fleet $^{2,23}$.

The design of hydrogen vehicles has been limited by the difficultly of storing the energy. Various innovative operating cycles have been successfully developed, but none have been commercially produced and marketed. With the advent of the CAAA, interest in hydrogen vehicles has been renewed ${ }^{6,12}$. 
Hydrogen fuel celis have been used since the early 1960's by NASA in the Gemini and Apollo missions. These cells were used to provide both electricity and drinking water for the astronauts ${ }^{24}$. Though application in the transportation sector has been very limited, recent advancements favorably demonstrate the advantages of hydrogen. Hydrogen fuel cells operate through a proton exchange membrane that combines hydrogen and ox: gen to form water, and produces electricity. The prototype vehicle was two to three times more efficient than conventional internal combustion engines, with significantly extended ranges. The range is approximately 1,000 miles. Battery-powered electric vehicles have a range of about 120 miles, a difference of about 8.6 times or 900 miles. This highly efficient fuel cell can also be operated in reverse to produce hydrogen, similarly to electrolysis. The hydrogen produced is stored in a tank filled with a finely grounded metal alloy that absorbs gaseous hydrogen and releases oxygen. During periods of non-driving and braking, when power is not required to drive the vehicle, the cycle is reversed to produce hydrogen fuel that is, in turn, used to produce electricity in the fuel cell. Additional experimentation suggests that heat generated by the hydrogen fuel cell could be used to heat the passenger compartment and the heat absorbed hydride could be used to provide cooling. This technology is available and several prototype vehicles have been constructed ${ }^{6}$.

Economically, the operating cost for the hydrogen fueled vehicles covers a wide range. Direct hydrogen fueled vehicles have an operating cost of about $\$ 2.90 /$ equiv gallon. Vehicles using the hydrogen fuel cell could have a cost of about $4 \mathrm{c} / \mathrm{mile}^{21}$.

Because of the significantly higher costs associated with hydrogen and the relatively early stage of development, hydrogen was removed from further consideration. It is unlikely that a supply of hydrogen will be available by 1995 , even if vehicles could be found.

Electric vehicle. While not specifically an alternative fuel, the electric vehicle must still be considered an alternative to a gasoli e or diesel fueled vehicle. The electric vehicle is driven by a rechargeable battery, which is ver, fir. Near term electric vehicles are powerea by electricity that is stored in rechargeable battery packs, though as discussed above, development is underway for a hydrogen fuel cell electric vehicle. Current vehicles use lead-acid batteries, but nickel-iron and sodium-sulfur batteries are expected to be developed within the decade. These new batteries will take longer to discharge, effective'y increasing the vehicle rar.ge. Current technology using very heavy lead acid batteries have a range limited to about 50 to 100 miles before recharging. Because of the long distances involved in driving to and from, as well as arcund, the INEL, it is unlikely that the electric vehicle will be a viable alternative to meet the goals. The electric vehicle requires an entirely new vehicle; it is not possible to convert a gasoline or diesel fueled vehicle ${ }^{25}$.

Several electric vehicles are under development. The G-Van, a one-ton van produced by Conceptor Industries, currently is the only EV certified to meet all U.S. Federal Motor Vehicle Safety Standards (FMVSS). Chrysler Corporation, in conjunction with Electric Power Research Institute (EPRI) and DOE, plans to introduce the TEVan, using a nickel-iron battery, in the mid 1990's. Ford Motor Company plans to introduce the EcoStar van, using a sodium-sulfur battery pack, in the mid to late 1990's. General Motors Corporation is designing a completely new concept vehicle, a two passenger electric vehicle, called the Impact. The Impact will use the better tested lead-acid batteries and is expected to be introduced in the mid-1990's. GM and Ford are also developing hybrid vans, capable of operating on electricity and recharging on gasoline ${ }^{15}$.

The voltage required for recharging EV batteries is 200/250-volt, single phase, 60 amperes (amp), power source. This voltage range is compatible with the U.S. standard voltage of $208 / 240$-volt, single 
phase 60 amp. A disadvantage with electric vehicles is that a fully discharged battery takes 8 to 10 hours to recharge. This is relatively impractical for vehicles that have such a limited driving range. Charging stations should be located indoors in a properly vented heated space to ensure full charge ${ }^{15}$.

Like the hydrogen vehicle, the electric vehicle is nominally a zero-emission vehicle. However, electric power, generated from fossil fuel, will not reduce net environmental emissions, but will change

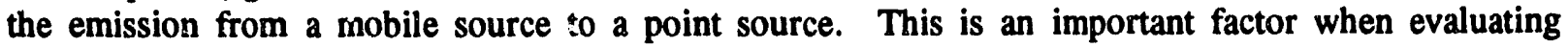
emissions ${ }^{16}$.

Several hazards are associated with EVs. Electric shock is a common problem. Shock can be avoided by knowledgeable maintenance personnel and maintenance schedules. Sulfuric acid contained in the lead-acid batteries can cause damage to the vehicle. Periodically checking batteries for acid leakage can prevent this damage. Hydrogen, an explosive gas, can be released during battery recharging, and explosions have occured with improper recharging. With a lower specific gravity than air, the vapor dissipates rapidly in ventilated garages ${ }^{25}$.

The cost of electric vehicles tends to be high. The G-Van is estimated to cost $\$ 50,000$ per vehicle. The mileage is about $1 \mathrm{mile} / \mathrm{Kwh}$, which is equivalent to about $15 \mathrm{miles} / \mathrm{gallon}$ gasoline. This compares with about 22 miles/gallon for a similar gasoline fueled vehicle. The range is about 60 miles between recharges under optimal conditions. Range is reduced by factors such as vehicle load, long distances at high speed, steep hills, cold temperatures, and the use of auxiliary equipment (e.g., heaters, air conditioning, windshield wipers, headlights, etc.). With lead-acid batteries, there is a one-mile reduction in range for each $5^{\circ} \mathrm{F}$ drop in temperature from $75^{\circ} \mathrm{F}^{15}$.

The factors which define whether EVs should be used in the vehicle fleet include distance, payload requirements, types of terrain, operating speeds, outside temperatures, and locations along the route for charging opportunities. Potential applications might include security patrols, plant maintenance activities, deliveries, and customer service calls. However, because of the limited range, and the limited availability, electric vehicles are unlikely to be suitable to meet the goals for either fuel reduction or near term alternative-fueled vehicles introduction. For these reasons, electric, vehicles were eliminated from further consideration.

\section{Considerations for Converting to Alternative Fuels}

In order to make a final decision on which alternative fuel would best serve the INEL, several considerations must be taken into account. Some of these considerations can be quantified, while others can only be qualitatively addressed.

Cost. Both capital and operating costs must be considered when selecting an alternative fuel. Capital costs include new vehicle costs, costs of conversion of existing vehicles, and the cost to establish the infrastructure. Operating costs include the costs for fuel, maintenance, training, insurance, etc. The resale value of retired vehicles must be considered.

Availability. The availability of the vehicle types used at INEL, as well as the alternative fuel will be an important part of the decision.

Suitability to INEL. Suitability includes such things as the travel range of a vehicle, where vehicles must be able to travel to and from the site. Because INEL has a mixed diesel/gasoline fleet, it would be 
desirable to have a single alternative fuel to replace both, which might limit the choice. The alternative fuel must work over the temperature range of $-40^{\circ} \mathrm{F}$ to $100^{\circ} \mathrm{F}$ expected in Idaho.

Emissions. Emissions will vary with different fuels and would seem to be an important consideration. However, federal and state regulations for emissions from AFVs are being, developed. These will dictate maximum levels for all emissions from alternative-fueled vehicles. Therefore, while some alternative fuels will require more emission abatement add-ons to the vehicle than others, the differences will be reflected in the vehicle purchase cost.

Reliability. Reliability of the vehicles is an important consideration, but will be difficult to evaluate at this time, because none of the alternative-fueled vehicles has been tested extensively enough.

Safety. Safety, which encompasses both the vehicle itself and the filling station, is also an important consideration that is difficult to evaluate. However, it is expected that all alternative-fueled vehicles and facilities will be required to meet all relevant federal and state safety standards before they will be made available. As with emissions, inherent advantages in safety of one alternative fuel over another will be reflected in the vehicle or infrastructure costs.

Acceptance. Until alternative-fueled vehicles have been in use for some time, it will be difficult to make more than a general evaluation concerning acceptance.

Summary. For the situation at the INEL, it will be difficult to convert the diesel buses to an alternative fuel in time to meet the 1995 goals, so the $10 \%$ reduction in fuel use will need to be accomplished through a reduction in gasoline use and/or a reduction in the number of miles driven. One scenario being considered would have the $10 \%$ reduction come entirely from gasoline, which implies a reduction in gasoline use of $30 \%$, or 153,000 gallons. It has been estimated that as newer vehicles with improved gasoline mileage are purchased, and improved fuel conservation methods are used, a 10\% reduction in gasoline use could be achieved. However, the remaining $20 \%$ reduction will require substitution of alternative-fueled vehicles. To meet the new vehicle substitution schedule will require purchase of alternative-fueled buses as well as cars. It may be that a single fuel will not be suitable for both the near term and for the future. At some time in the future, there will be driving forces within the alternative fuels industry that lead to the adoption of a particular fuel for use by the general public. These may or may not be the same as for the INEL fleet, where goals are being mandated before all the research concer: ing alternative fuels has been completed. It may be necessary for the INEL to select one fuel to meet the $10 \%$ conventional fuel reduction, even knowing that another fuel will be more suitable in the future. To meet these goals, in the most cost-effective manner, requires an analysis of which alternative fuel best meets the overall needs of the INEL fleet. 


\section{SYSTEMS ANALYSIS MODEL}

\section{Systems Analysis Approach}

This study used the systems thinking approach espoused by the book The Fifth Discipline $e^{26}$ and pioneered by Jay W. Forrestor. A "system" is defined to be "a collection of parts which interact with each other to function as a whole". The traditional approach to problem analysis involves breaking a large problem down into small parts, each of which is analyzed by itself. The implicit assumption of the traditional approach is that a system is the "sum of its parts". In contrast to the traditional approach, "Systems thinking" recognizes that the interactions among those parts are usually extremely important and cannot be neglected. "Systems thinking" also recognizes that, in the real world, cause and effect are often widely separated in time and space. "Systems thinking" also allows for the inclusion of "soft variables" such as "customer perception" or "employee morale" which may not be precisely quantified but which can have a big impact on the dynamic behavior of a system.

The study of many different kinds of systems has shown that all systems, as defined above, contain certain basic organizational structures; such as, positive feadback loops and negative feedback loops.

The concepts associated with "systems thinking" may not be new but they are very profound and are often overlooked during a decision making process. The recent development of computer-based system analysis tools has made it easier to apply these important concepts.

Figure A1 (Appendix A) is a high level representation of the process addressed by this study. It consists of a set of variables which interact with each other to form a set of closed loops. An arrow between two variables indicates a cause and effect relationship between the variables. The diagram is described in more detail in Appendix A. It represents the fundamental thinking behind the detailud model. The development of this high level model helped to identiry potential leverage points, which are actions that can be taken to move the system toward the desired results. In this case, the desired result is assumed to be a fleet of alternative fuel vehicles (AFVs). The development of the model also helped to clarify the following about the process of introducing AFVs.

- Without external intervention, the AFV customer acceptance level must meet or exceed the current acceptance standard before there is a significant number of AFVs in service.

- There is currently a customer acceptance gap between AFVs and current vehicles, which may be temporarily overridden by Federal directive. The customer acceptance gap is the difference between the AFV acceptance level and the current acceptance level of gasoline and diesel vehicles. The current acceptance level for gasoline and diesel vehicles is based on attributes, such as cost per mile, reliability, safety, performance, emissions, and fuel availability.

- As the number of AFVs in service rises, the AFV customer acceptance level will tend to increase after a time delay. All the main components of custonier acceptance, as outlined above, are expected to improve as a result of increased numbers of vehicles in service. However, this improvement may not happen until after a significant time delay. Also, the most significant causes for improvements in customer acceptance may be external to the INEL. Improvements in AFV quality are more dependent on the global number of AFVs in service than on the number of vehicles in the INEL fleet. 
- If the Federal initiative can continue long enough to close the acceptance gap, the desired effect will become self sustaining. After the AFV customer acceptance level rises to meet the standard, then the system will sustain an increasing number of AFVs (without external intervention) until the entire fleet is AFVs. If the AFV customer-acceptance level remains below the standard, then the number of AFVs will decrease toward zero unless there is continued intervention from a Federal directive.

- The leverage points are actions that will help to close the AFV customer acceptance gap faster, and therefore make the system self-sustaining sooner.

\section{The I-think ${ }^{\mathrm{TM}}$ Tool}

The tool chosen for this study is named I-think ${ }^{\mathrm{TM}}$ and is a commercial product from High Performance Systems, Inc. of Hanover, $\mathbf{N H}^{27}$. It is designed for Macintosh desk top computers and is intended primarily as a decision making aid. The tool was designed for the "systems thinking" approach described above. It is particularly well suited for quickly creating a working model of a system. For more detail on I-think ${ }^{\mathrm{TM}}$, see the I-think ${ }^{\mathrm{TM}}$ Users Guide.

The user of I-think ${ }^{\mathrm{TM}}$ begins by drawing a diagram of the system under study on the computer screen. The diagram is made from a small set of basic building blocks. The building blocks are: (a) stocks, (b) flows, (c) converters, and (d) connectors. The stocks, flows, and converters are all system variables which must be given names by the 1 -think ${ }^{\mathrm{TM}}$ user. A flow depicrs an activity that feeds into and out of a stock. A stock is a storage place and generally acts like an integrator. A converter is a generalized variable. A connector is used to link stocks, flows, and converters to other converters. A connector implies an input or an output. The tool allows for some variety in types of stocks and has built in functions that provide for the programming of complex formulas within converters and flows.

Each stock, flow and converter can be defined more completely by double-clicking to open a window associated with it. The window associated with each building block provides for documentation of assumptions, the defining of formulas, and the selection of other options.

The tool will run a simulation of the model when the diagram is complete and when all the inputs implied by the connectors are resolved with valid formulas. The tool provides a method for plotting the value of any variable over simulated time. The tool also provides the capability to run a series of simulations where the values of input variables are varied over a range of values or a probability distribution (that is, sensitivity analyses).

I-think ${ }^{\mathrm{TM}}$ version 2.0.1 was used for this analysis. It is especially good for small models, but for larger, more complex models, it has a sectoring feature that allows the model to be divided into sectors, which can each be run independently. While I-think ${ }^{\mathrm{TM}}$ can also be used to create very large models with hundreds of variables, such a model can become very difficult to manage, and the computer run time increases significantly. The model created for this study has 190 variables and is large enough to cause noticeable computing delays on a Macintosh IIci, but for the most part, I-think ${ }^{\mathrm{TM}}$ was very useful for the purposes of this study. I-think ${ }^{\mathrm{TM}}$ also provides output that can be exported to graphics packages and spreadsheets. 


\section{Model Description Overview}

A detailed description of the system; analysis model that was developed for this study is found in Appendix 1. Appendix 2 contains the diagrams and equations that are the actual implementation. The model was implemented on a Macintosh IIci computer.

The model represents the process of changing the INEL gasoline and diesel fueled fleet into a fleet of AFVs. The process is modeled on a year by year basis for 20 years into the future to cover the range of 1993 to 2013. The model is designed to be generic enough to be used for any alternative fuel so there can be direct comparisons between alternatives. All the numbers associated with the alternative fuels are in units of equivalent gallons, where an equivalent gallon is defined to be the amount of alternative fuel that produces the same amount of energy as a gallon of gasoline, or about $890,000 \mathrm{Btu}$.

The major components of the model are:

1. Vehicle flow.

2. Cost flow.

3. Introduction process.

4. Customer acceptance.

5. Emissions (atmospheric pollution).

6. Control panels.

Vehicle flow is modeled by dividing the fleet into three main types: cars, buses, and mid-size vehicles. The flow of each of the three types is modeled separately. The vehicle flow model is a representation of how vehicles flow from "new vehicles" to "vehicles-in-service" and then to "retired vehicles". It includes a conversion process to convert gasoline/diesel type vehicles into alternative fuel type vehicles. The vehicle flow is controlled by (a) demand for vehicles, (b) the average time in service, and (c) the alternative fuel introduction process.

Cost flow modeling is the year by year addition of all the costs associated with the process. These costs include (a) the cost of constructing an alternative fuel infrastructure, (b) the price of new and retired vehicles, (c) conversion costs, (d) fuel costs, and (e) annual maintenance costs. The costs are also calculated as a cumulative present value where the effects of inflation and the cost of capital are included.

The introduction process model includes (a) a delay associated with constructing an infrastructure, (b) a year by year plan for the fraction of new vehicles that are to be alternatively fueled, (c) a year by year plan for the fraction of gasoline/diesel vehicles that are to be converted to alternative fuel, and (d) a feedback mechanism that limits the actual purchases and conversions according to the level of customer acceptance. The purchase and conversion schedules drive the introduction process, and should be consistent with the Federal directives.

The emissions model calculates the amount of atmospheric emissions predicted each year from all INEL vehicles. Three types of emissions are calculated: nitrogen oxide compounds $\left(\mathrm{NO}_{\mathrm{x}}\right)$, carbon monoxides (CO), and nonmethane hydrocarbons (NMHC). These three components were chosen, because there are emissions standards for them. The amount of each type of fuel consumed each year is included in this part of the model. 
The control panels are included in the model to clarify the input variables and to make the model easier to use. All the input variables are included in the control panels. Every input variable may be a function of time.

\section{Assumptions and Inputs}

This section will present the assumptions used in developing the model, and the input data that leads to a nominal "best guess" case. In Appendix A-4 details of the input data are given with both the nominal values and the minimum and maximum anticipated values are provided.

\section{Assumptions}

The following assumptions were made in developing the model. Some are straightforward, while others represent a choice of options. Other options exist represent different scenarios and some of the other options were analyzed to see what effect they might have.

- The alternative fuels will be technically feasible for each of the vehicle types under consideration.

- AFVs will be acceptable to users. The model allows for a varying level of acceptance, but there is no data to quantify a particular level, and Federal guidelines will mandate that vehicles will be acceptable.

- All environmental and safety regulations will be met. Although the model will calculate emission levels for different alternative fuels, it is somewhat of a moot point, because, while there will likely be differences among the various AFVs, Federal regulations will dictate a minimum standard that all vehicles must meet. Therefore, vehicles that cannot meet the standards, will require that pollution abatement equipment be added, similarly to the way current GFVs have today. These add-ons will represent an increase in the purchase cost for vehicle. Safety concerns will be similar, with differences being accounted for in different vehicle costs.

- Only one alternative fuel will be selected. It was decided that the added complexity and cost of a multi-fueled fleet would not be worth the potential improvement in performance.

- The demand for vehicles will remain constant at 1991 levels.

- The number of miles driven for each vehicle type will remain constant. This assumption is clearly open to debate, because one way to meet the $10 \%$ fuel reduction would be to reduce the number of miles driven by $10 \%$. However, there is no current plan to do so.

- The years of service for all vehicles is the same and remains constant with time. The model has the ability to change the service time, but no logical schedule exists to say that there will be change.

- Only new gasoline cars will be converted to alternative fuels. This decision was made by the fleet management. Because vehicle conversions would not be done at INEL, this says that, in effect, no conversion, as such, will be done. The only real effect is to have the cost of new vehicles change with time as they change from conversions of GFVs to specifically designed AFVs 
- No buses will be converted from diesel to an alternative fuel. All alternatively fueled buses will be purchased new.

- All costs are in 1992 dollars. Inflarion and the time value of money are includirig in the cumulative present cost.

\section{Inputs}

Input data for the model are presented in Appendix D. 


\section{ANALYSIS RESULTS}

As stated earlier, the objective of this analysis was to provide guidelines to the INEL fleet management to meet goals for reducing gasoline and diesel fuel usage, and to implement AFV purchase plans. Because of the many variables involved, it is not possible to recommend a single alternative fuel as the best to serve the needs of the INEL. Therefore, the results will be presented on a "best guess" basis. For each of the input variables there is a nominal value that represents the best available data known at present. There is also a minimum and maximum value for each variable that represents the best and worst case anticipated for that variable. The range can be quite large, because of the uncertainty in much of the data associated with all of the alternative fuels.

With the many potential input variables available in the simulation on I-think ${ }^{\mathrm{TM}}$, it is possible to generate a bewildering assortment of results. Although there are numerous scenarios possible for implementing AFVs, a scenario was selected that represents the best current thinking of how AFVs will be brought into the INEL fleet. The scenario reflects both Sections 10 and 11 of Executive Order 12759 as described previously. The $10 \%$ reduction in gasoline and diesel fuel use is planned to be accomplished entirely by about a $30 \%$ reduction in gasoline use, with $10 \%$ resulting from improved conservation methods, and 20\% through the use of AFVs.

Figure 1 shows the rate of introduction of AFVs as the percent of new vehicles that use alternative fuel. Between 1993 and 1998, the increase in percent of new AFVs is based on Sectivin 11 of Executive Order 12759, which calls for $50 \%$ of new vehicles to use alternative fuels. After 1998, the trend was continued until all new vehicles are alternatively fueled, which occurs about 2001 . Figure 1 also shows the percent of total cars and buses in service that are alternatively fueled. Under the scenario of $100 \%$ of new cars to be alternatively fueled by 2001 , the fleet becomes $100 \%$ alternatively fueled cars by 2008 and $100 \%$ alternatively fueled buses by 2013 . If the decision is made to maintain the new car purchases at $50 \%$ AFVs after 1998, then the curves for in services vehicles will level off at $50 \%$ alternatively fueled cars and buses by about 2005 and 2010 respectively.

Figure 2 shows gasoline and diesel fuel use as a function of time for the scenario in Figure 1, where miles per gallon and miles per vehicle are held constant. At present, the total for all fuels equals the total for gasoline and diesel, because no alternative fuels are currently used. With time, gasoline and diesel use falls as alternative fuel use rises. It can be seen that by 1995 , gasoline and diesel use has fallen by only about $5 \%$, which is not consistent with the $10 \%$ reduction goals of Section 10 of Executive Order 12759 . To meet the $10 \%$ reduction goal by 1995 , the introduction of AFVs will have to be accelerated, and/or the average gasoline and diesel use per vehicle will have to be reduced through better mileage or fewer miles driven. Figure 3 shows the annual fuel use for a scenario where the 1995 goal for fuel use reduction is met.

Because cost is an important factor in determining which fuel is most suitable, the annual incremental costs were calculated for each alternative fuel. The results are plotted in Figure 3 for each fuel. The incremental cost is the increased cost for the INEL fleet using alternative fuel rather than gasoline or diesel. Therefore, in Figure 4, each curve represents the cost penalty for using an alternative fuel. The initial high peak at 1994 represents the one-time cost to provide the infrastructure. Thereafter, the incremental cost reflects the gradual introduction of AFVs. From the graph, it can be seen that the cost for the alcohol fuels and for LPG tend to rise to a plateau. The higher cost for the alcohols and for E85 versus M85 is primarily because of the higher cost of fuel. Costs for both natural gas fuels reach a peak 
in about 2004, and then begin to decrease through the remainder of the time of the analysis. This rise and then fall in cost for CNG and LNG vehicles reflects a trade-off between the cost of the vehicle and the cost of operation. Initially the rate of increase in number of AFVs is greater, and the higher cost of AFVs compared with GFVs, outweighs the lesser cost of LNG or CNG. Eventually, the rate of increase in numbers of AFVs falls, and the lower cost of fuel becomes dominant, so the total annual cost approaches that for gasoline. This is not true for the alcohol fuels, because the cost of fuel is much higher.

A primary result desired from the analysis was a determination of the incremental capital and operating costs to implement the fuel substitution plan to meet the mandates. Incremental cost is the cost above and beyond the cost for the gasoline and diesel fueled fleet. There are two parts of the cost: a one-time cost of the infrastructure, and the ongoing cost for purchase of new vehicles and operation of the INEL fleet as a whole. The incremental costs for each alternative fuel is shown in Figure 4. However, as mentioned above, there is a potential range of costs for each fuel type. An example is shown in Figure 5, where the maximum (most pessimistic) and minimum (most optimistic) incremental costs are plotted with the nominal costs for LNG. Although not shown fnr purpose of clarity, the curves for the other fuels show similar ranges. Indeed, the range for gasoline and diesel fueled vehicles shows a significant error band of $\$ 3.4$ million, which is also unlikely to be that large. It is apparent that the potential error band is large enough to encompass the nominal curves for all the fuels as shown in Figure 4. However, it is unlikely that the uncertainties of all the input variables that affect cost will coincide in such a way as to create the large error band shown. It is more likely that there will be some pluses and some minuses that will tend to cancel each other out, thereby making the trend in total cost closer to the nominal value.

Figure 4 shows that the infrastructure cost, assumed to occur in 1993, ranges from about $\$ 600,000$ for LNG to $\$ 2,600,000$ for E85. In $: 994$, the first year of implementation, the annual costs are very close at about $\$ 100,000$ for all the alternative fuels, because the number of AFVs is small. By 1998, when $50 \%$ of all new vehicles are to be alternatively fueled, the incremental annual cost ranges from about $\$ 250,000$ for LPG to $\$ 600,000$ for $\mathbf{E 8 5}$. At the end of the 20 year analysis period, the range has widened from near zero for LNG to $\$ 1,500,000$ for E85.

As another comparison, Table 2 shows the average cost per mile calculated by the model for each fuel type. Included in the cost per mile are the annualized vehicle purchase price, fuel, maintenance, training, etc. These costs again show E85 to have the highest cost for all vehicle types with M85 being second highest. There is little difference among the remaining fuels.

Table 2. Cost per Mile Comparison

\begin{tabular}{lllllll}
\hline $\begin{array}{c}\text { Vehicle } \\
\text { Type }\end{array}$ & $\begin{array}{c}\text { Gasoline } \\
\text { Diesel } \\
(\$)\end{array}$ & $\begin{array}{l}\text { CNG } \\
(\$)\end{array}$ & $\begin{array}{l}\text { LNG } \\
(\$)\end{array}$ & $\begin{array}{l}\text { LPG } \\
(\$)\end{array}$ & $\begin{array}{l}\text { E85 } \\
(\$)\end{array}$ & $\begin{array}{l}\text { M85 } \\
(\$)\end{array}$ \\
\hline Cars & 0.12 & 0.15 & 0.14 & 0.16 & 0.19 & 0.18 \\
Midsize & 0.26 & 0.27 & 0.25 & 0.30 & 0.39 & 0.34 \\
Buses & 0.72 & 0.73 & 0.72 & 0.71 & 0.83 & 0.77 \\
\hline
\end{tabular}




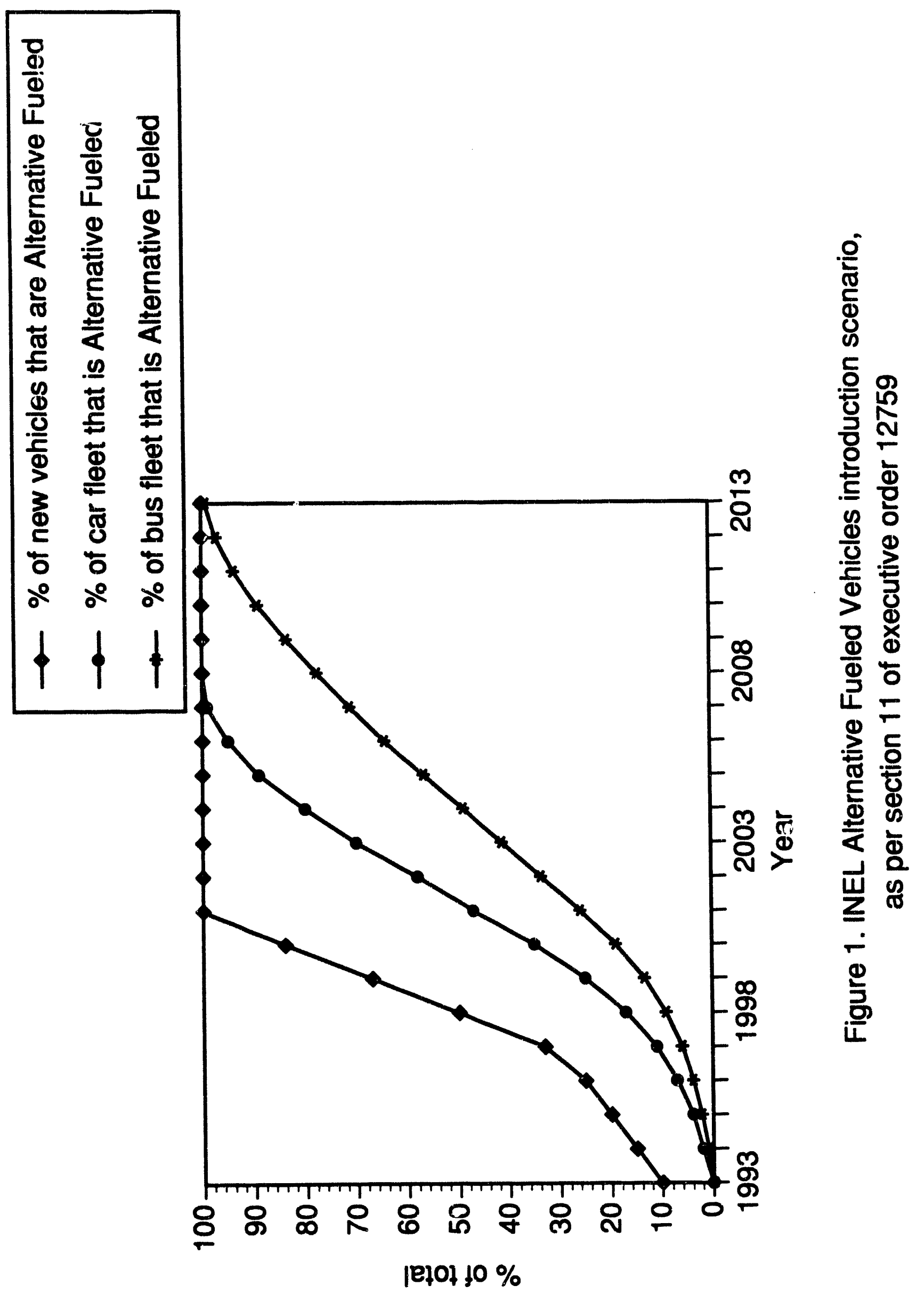




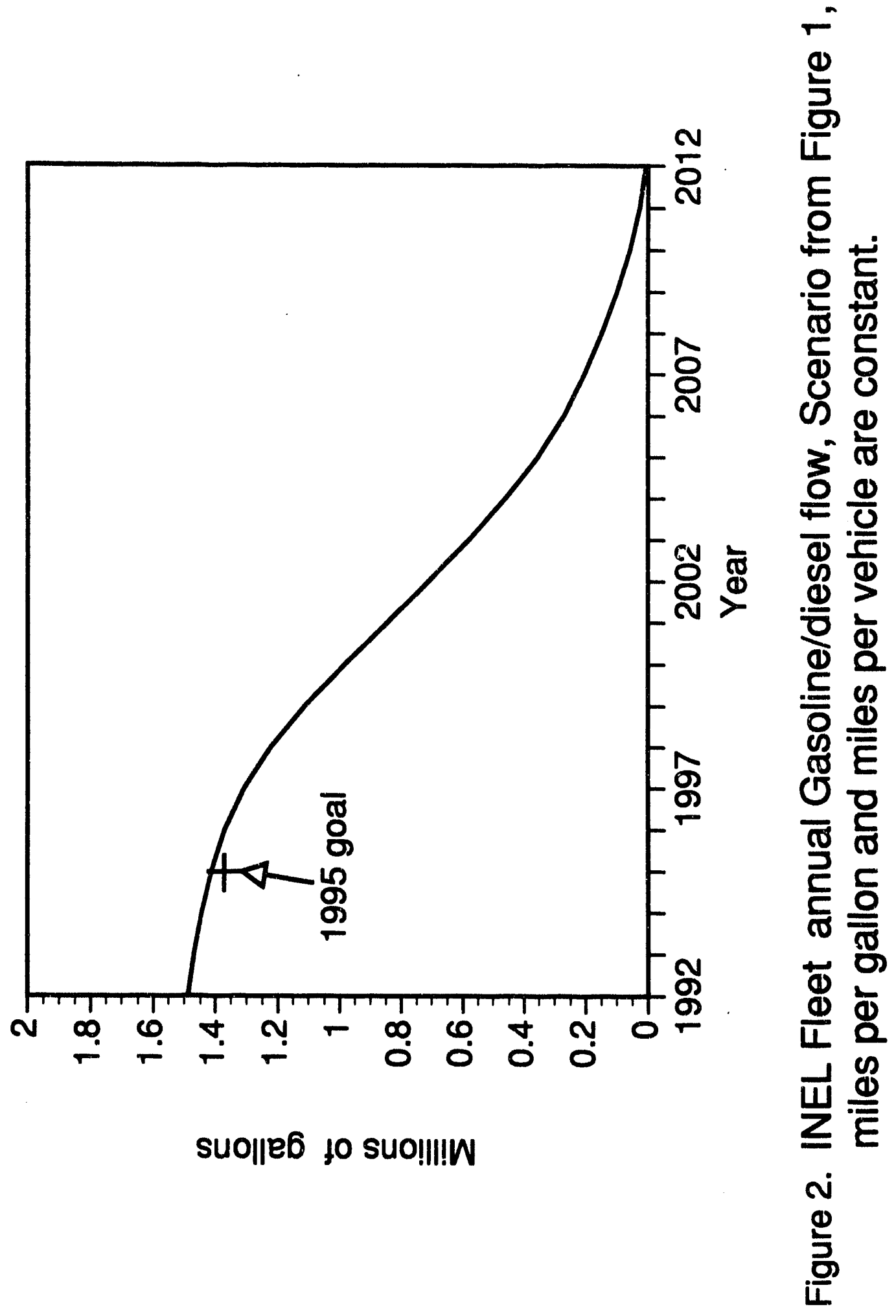




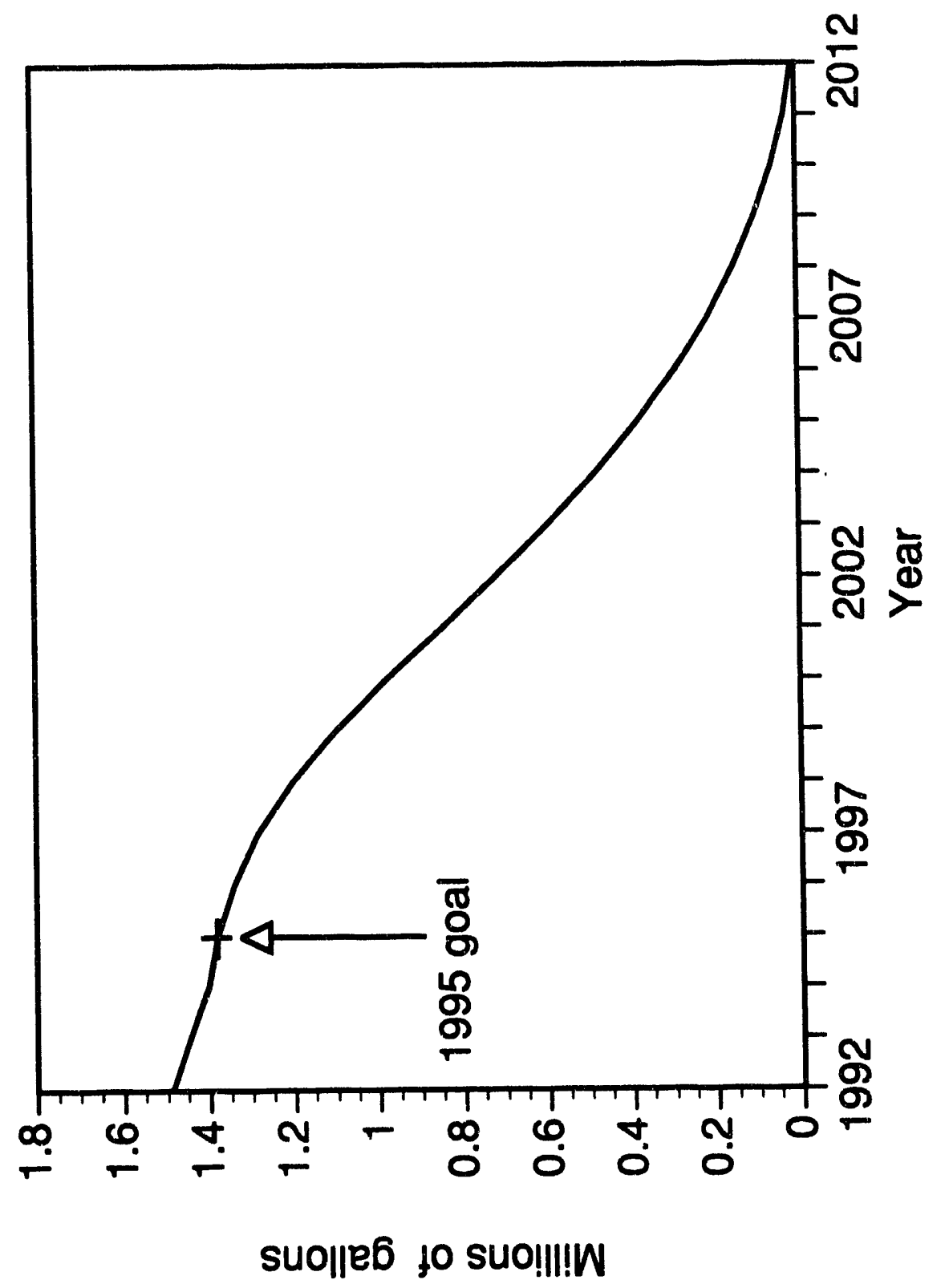

ত্

요

요

을

은

.

号

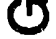

雨

E

离

는

$\underline{z}$

के

은

suo||e6 to suo!!I!W 


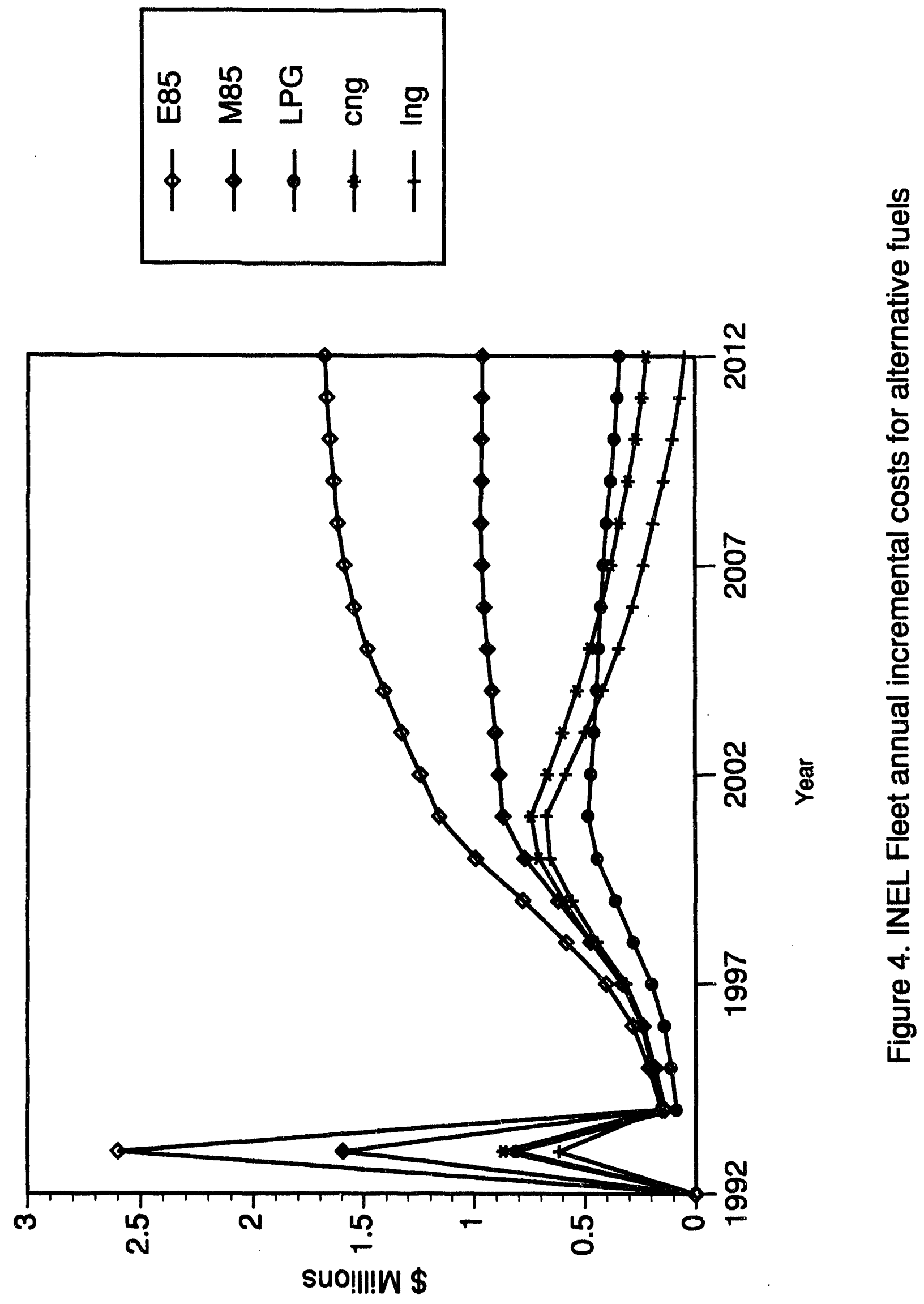




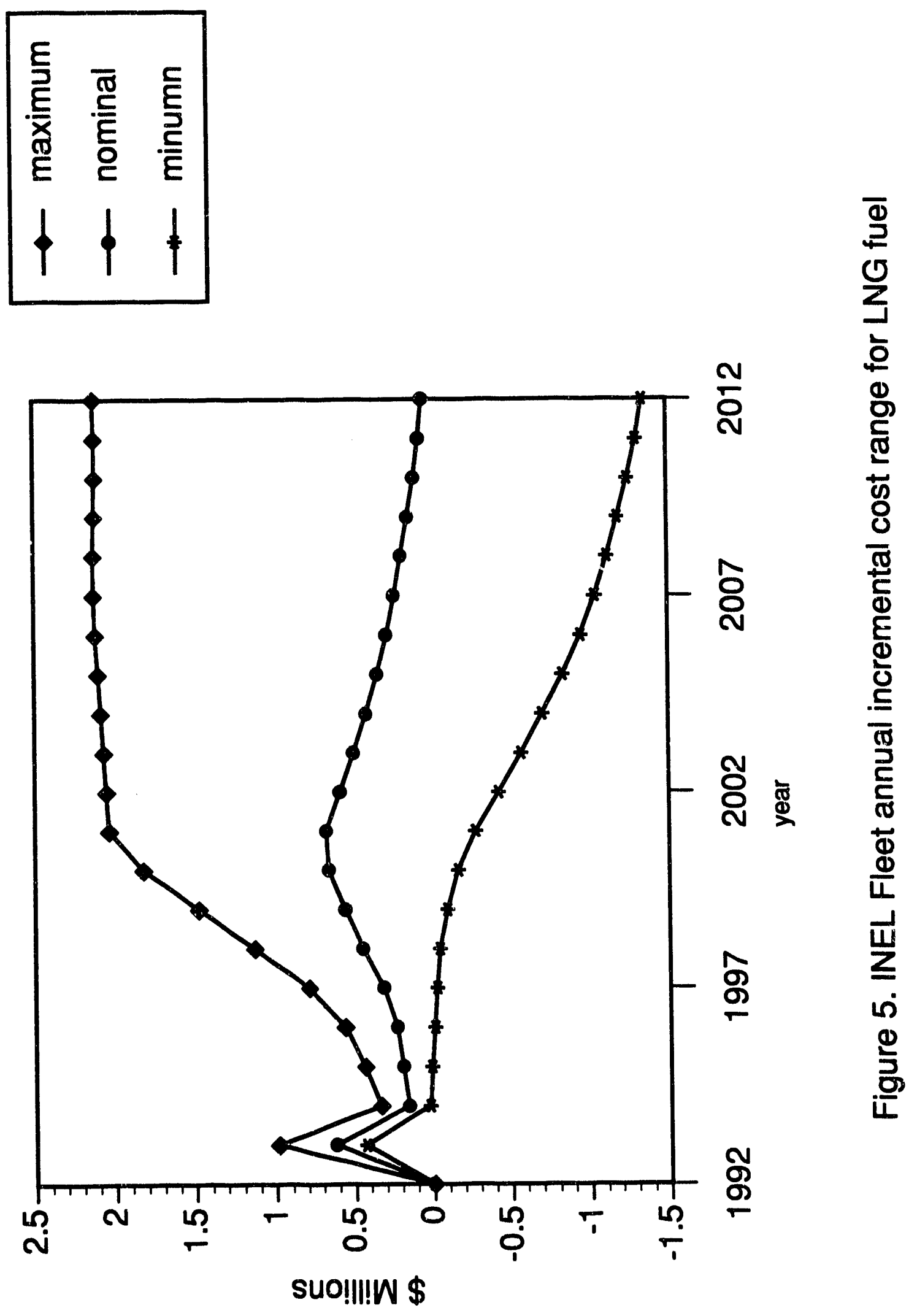


Table 3 shows the cumulative present cost for each alternative fuel as compared with gasoline/diesel for the entire 20 year period assuming an $8 \%$ discount rate. The cumulative present cost is the amount of money that would have to be set aside in 1992 to cover all the expected costs for the next 20 years. The $8 \%$ discount rate is the assumed difference between the prime annual interest rate and the annual rate of inflation. Cumulative present cost (or cumulative present value) is often used to choose among longterm investments. In this case, the lowest cumulative present cost is LPG, because it has the lowest costs in the early years. However, LNG has nearly as low a cumulative present cost as LPG, with CNG being only slightly higher.

Table 3. Cumulative Present Cost Comparison versus Gasoline/Diesel, 20 Years at $8 \%$

\begin{tabular}{lc}
\hline Fuel Type & $\begin{array}{c}\text { Cumulative Present Cost } \\
\text { (Million \$) }\end{array}$ \\
\hline CNG & 4.68 \\
LNG & 3.81 \\
LPG & 3.68 \\
E85 & 10.99 \\
M85 & 7.38 \\
\hline
\end{tabular}




\section{CONCLUSIONS}

Regardless of the results presented above, it must be understood that the primary driving force behind implementation of AFVs will be legislation and regulations. Therefore, even though the results indicate that any alternative fuel will incur a cost penalty compared with gasoline or diesel, that penalty will have to be paid to comply with the goals.

This study showed that LNG, CNG, and LPG appear to have the lowest cost penalty for the INEL fleet. However, because the INEL has had poor experience with LPG in past tests, and LPG will likely have limited availability over the long term, LPG is not recommended as a long-term solution. Therefore a natural gas fuel will likely be the alternative fuel of choice. The alternative fuel with the lowest cost penalty and with sufficient long-term fuel availability is LNG. Because the technology for CNG is more advanced than for LNG, the first AFVs should probably be CNG with conversion to LNG as the technology becomes developed. 


\section{Appendix A}

\section{Detailed Model Description}

\section{High-level diagram}

Figure A1 is a high level representation of the model for the INEL alternative fuel vehicle (AFV) implementation process. It is the basis for the detailed model that was implemented with the I-think ${ }^{\mathrm{TM}}$ tool. It consists of a set of variables which interact with each other to form a set of closed loops. An arrow between two variables indicates a cause and effect relationship between the variables. An arrow with an " $s$ " means that the affected variable changes in the same direction as the cause variable. (as the cause variable increases the affected variable increases, and as the cause variable decreases the affected variable decreases) An arrow with a "o" symbol means the affected variable changes in the opposite direction as the cause variable. If a loop has all " $s$ " arrows or an even number of "o" arrows, it is a regenerating loop (or a positive feedback loop). In this kind of loop, all the variables increase continually once it has started increasing, or all the variables decrease continually once it has started decreasing. If a loop has an odd number of " 0 " arrows it is a balancing loop (or a negative feedback loop). This kind of loop tends to be stable.

The left half of Figure A1 is a set of balancing loops which keeps the fleet size equal to the demand (demand is defined as the number of vehicles needed in the fleet). The fleet size is the sum of the number of AFVs and the number of gasoline/diesel vehicles (GDVs). The number of AFVs is initially zero. As vehicles are retired or as the demand changes, new vehicles are purchased to match the demand. An increase or decrease in the number of vehicles of each type will cause a corresponding increase or decrease in the number of vehicles retired after a delay equal to the time the vehicles are in service. The type of the new vehicles is determined by federal directive and the customer acceptance gap. In the absence of a federal directive, the customer acceptance gap will cause the new vehicles to be the type with the highest acceptance level, which is initially GDVs. The Federal directive is an input to the model and is a fraction (a number between 0 and 1 ) of the new vehicles which are planned to be AFV type. The AFV fraction increases during the first 6 years, becoming 0.5 by 1998 .

The customer acceptance gap is the difference between the AFV customer acceptance level and the GDV customer acceptance level. The AFV customer acceptance variable is an index which is a composite of all the attributes of the AFV vehicles. If the attributes are normalized to the gasoline/diesel standard, then the AFV acceptance index equal to 1 implies an equal level of acceptance. The simulation models the customer acceptance level as a normalized function of reliability, safety, and quality relative to the gasoline/diesel standard. The cost-per-mile component of customer acceptance is modeled by calculating the total cost per mile per year using the appropriate cost inputs. The fuel availability component is modeled with a delay for infrastructure construction and by the cost of the infrastructure. The emissions component is modeled assuming that the federal emissions standards will be met by the year specified by the standard.

The list of potential leverage points is the set of actions which can be taken to move the system toward the desired results. In this case, the desired result is assumed to be a fleet of AFVs. 


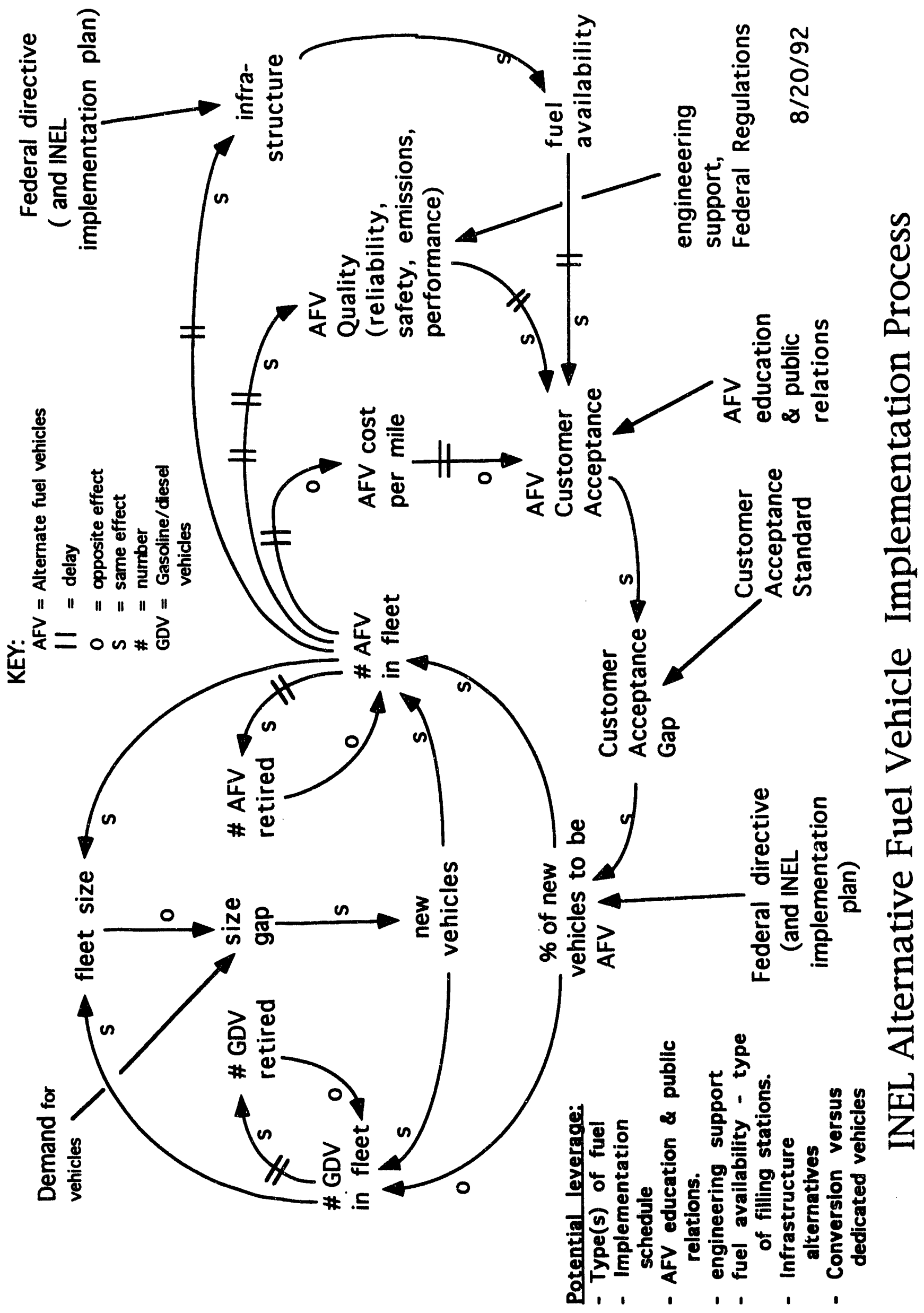




\section{I-think ${ }^{\mathrm{TM}}$ model implementation}

The I-think ${ }^{\mathrm{TM}}$ simulation contains separate models for cars, midsize vehicles, and buses to allow for differences in the value of the variables, but the structures of all the models are identical. The model, includes six basic vehicle types:

- Gasoline cars.

- Gasoline midsize vehicles.

- Diesel buses.

- Alternatively fueled cars.

- Alternatively fueled midsize vehicles.

- Alternatively fueled buses.

To compare the different alternative fuels, the appropriate input variables can be modified. The basic unit of time for the model is one year and it is setup to cover a period of 20 years from the base year, which for this analysis is 1993 . Any of the variables for the model are easily plotted over time or can be placed into a spreadsheet for further analysis. The diagrams and equations in Appendix 2 contain the complete model for a single alternative fuel.

Control Pane/s. I-think ${ }^{\mathrm{TM}}$ control panels are created to contain all the required input variables to the model. Each variable is documented within the model and can be easily changed as needed for different scenarios.

Vehicle Flow Model. The vehicle flow model contains sectors titled: "cars", "buses", and "midsize vehicles". The model assumes that a given vehicle type is in service for a fixed length of time. The cars sector, bus sector, and midsize vehicle sector have separate and identical vehicle flow models. The demand for each vehicle type is currently a constant and is set to the 1991 values, because that is the reference year for the fuel reduction goals. The vehicle flow model assumes that conversions from gasoline/diesel to alternative fuel vehicles is only done with new gasoline/diesel vehicles. The gasoline/diesel vehicles in service is initially set to the demand, and the number of alternate vehicles in service in initially set to zero. The vehicles flow into service with new purchases, and conversions. The vehicles flow out of service when it is past the fixed age limit. The age distribution of gasoline/diesel vehicles is assumed to be uniform initially.

Cost Flow Model. Cost is modeled in the sectors titled: "car cost", "bus cost", "midsize vehicle cost", and "totals". The cost flow model is a year by year summation of all known costs. Cumulative cost is calculated and the cumulative present cost is calculated. Cumulative present cost shows the effects of inflation and the time value of money by applying an annual discount rate (currently set at $8 \%$ ) to cost flow. All costs are in 1991 dollars. The annual maintenance cost includes all recurring costs such as, preventive maintenance, repairs, and insurance. The total costs are also calculated in terms of capital costs and operating costs.

Introduction Process Model. The alternative fuel vehicle introduction process is modeled in the sectors titled "alt fuel bus introduction process", "alt fuel car introduction process", "alt fuel midsize intro process", and "startup". These sectors provide feedback from the customer acceptance sectors to the vehicle flow sectors. The inputs to these sectors are: (a) the introduction plan, (b) the conversion plan, (c) the infrastructure delay, and (d) the customer acceptance index. The model sets an acceptance 
threshold which is a function of the number of alternatively fueled vehicles in service. The model assumes that the introduction plan will be followed initially no matter what the acceptance level is, but as the number of alternatively fueled vehicles in service increases, the acceptance threshold increases. The infrastructure delay causes the introduction plan to be delayed.

Customer Acceptance Model. The customer acceptance model consists of three sectors associated with cars, midsize vehicles, and buses, respectively. Inputs to the model are the expected reliability, safety, and quality indexes for each of the three vehicles types. These input values are normalized to the current gasoline/diesel vehicle attributes. For example, if the reliability of the alternatively fueled car is $10 \%$ higher than gasoline cars, the reliability input variable would be "1.1". The effects of improving technology can be modeled by making these numbers a function of time. The time it takes for people to adjust to something new is modeled with an exponential smoothing function using "people adjustment time".

Emissions and Fuel Flow Model. Atmospheric emissions are modeled in each of the three emissions sectors. There is one sector for each of the three pollutants addressed by the federal vehicles emissions standards: nitrogen oxides $\left(\mathrm{NO}_{x}\right)$, carbon monoxide $(\mathrm{CO})$, and nonmethane hydrocarbons (NMHC). Fuel flow is determined from the total miles driven by each vehicle type and its respective mileage. For M85 and E85, the fuel flow model accounts for the $15 \%$ gasoline in the fuel. The amount of fuel used each year by each type of vehicles is calculated, and then the total emissions is calculated based on the expected emissions per gallon of fuel for each vehicle type. 
Appendix B

Model Diagrams \& Equations

B-1 

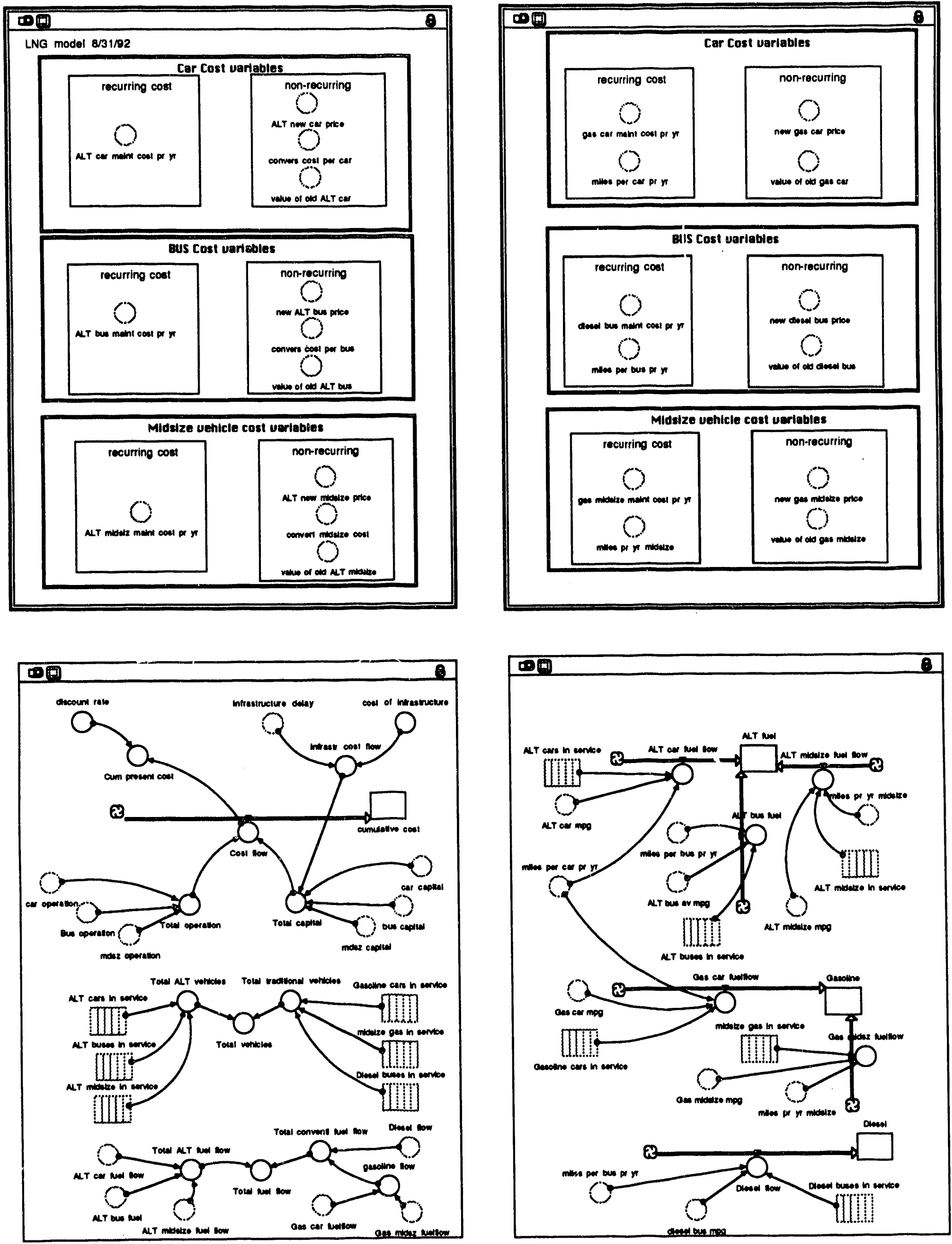

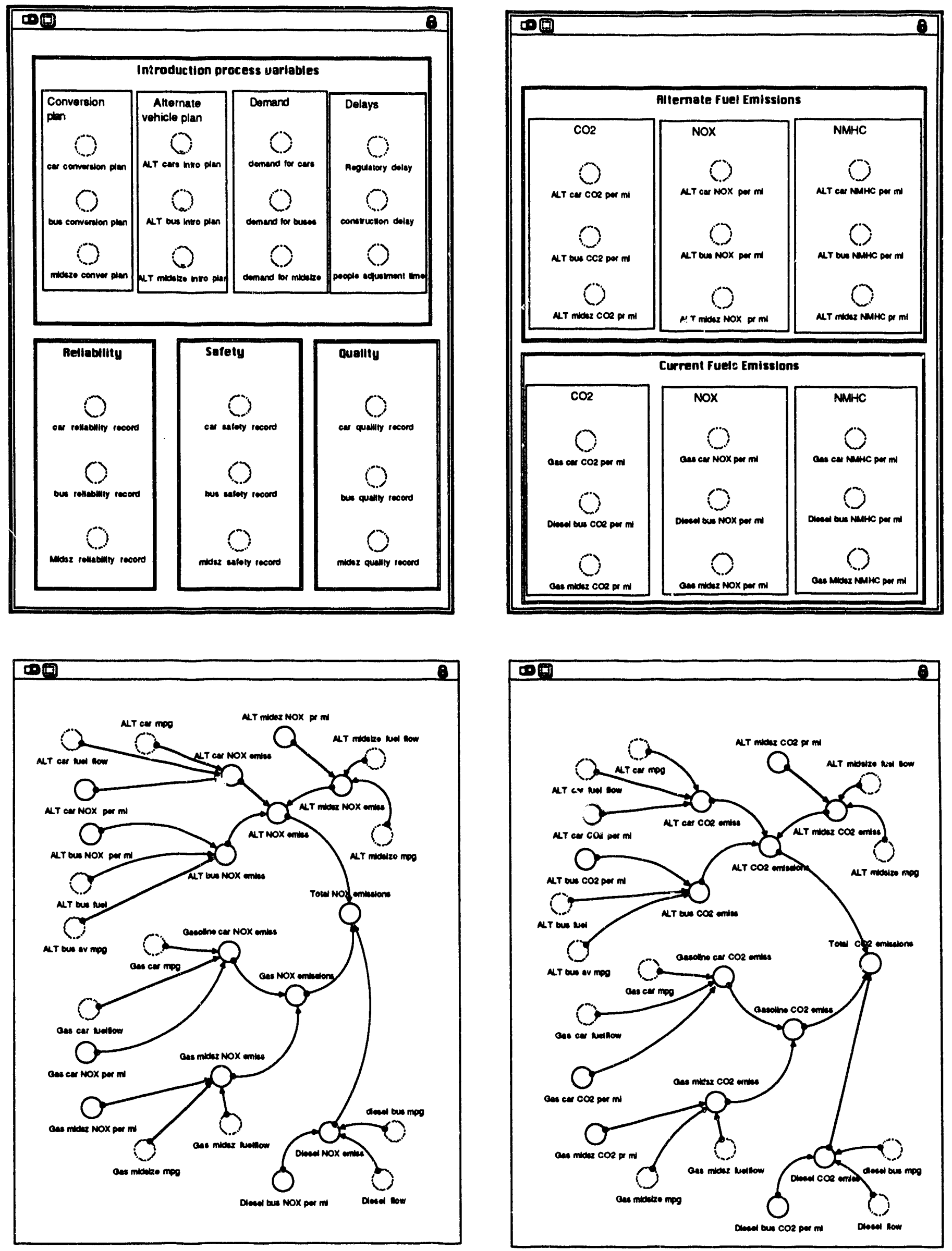

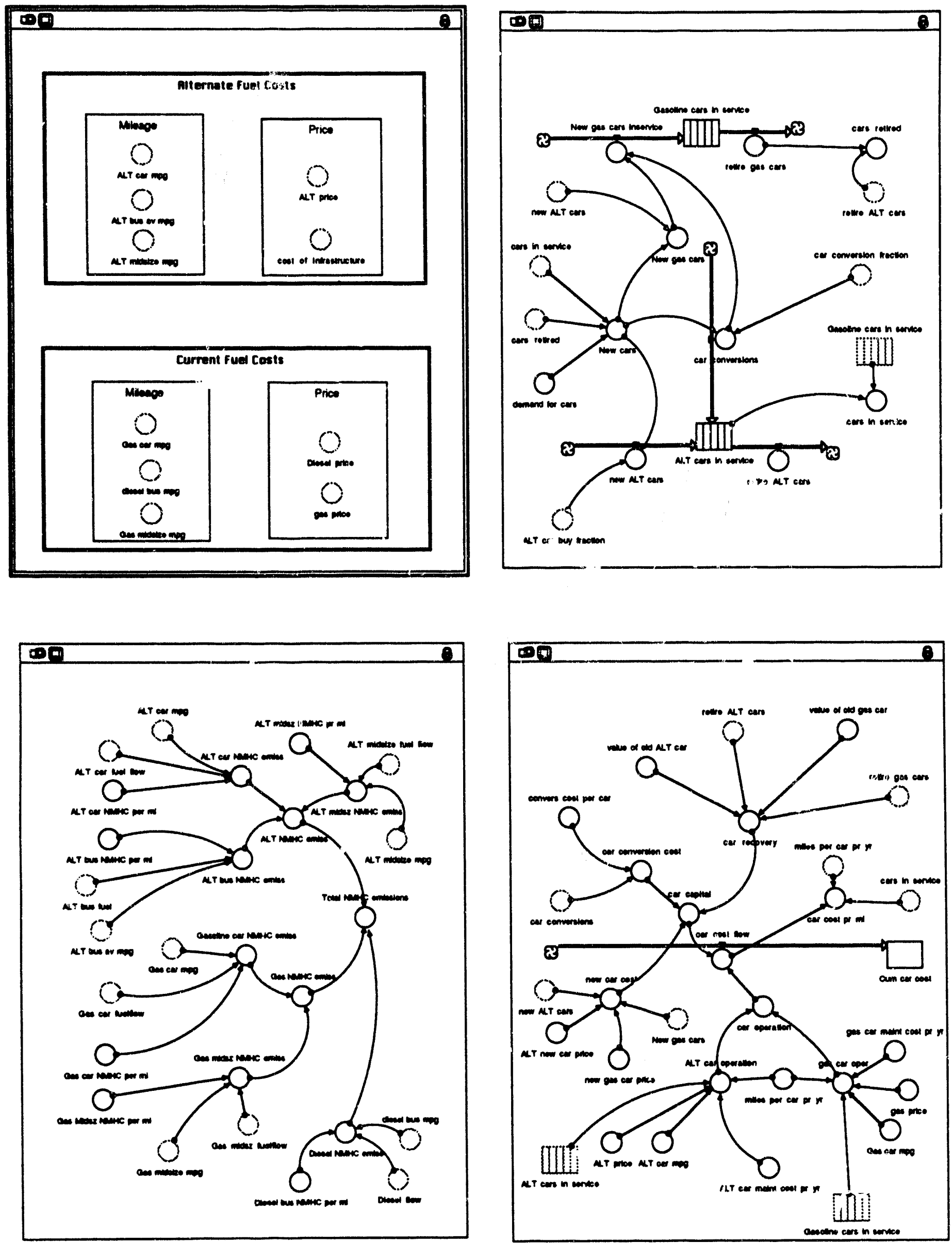

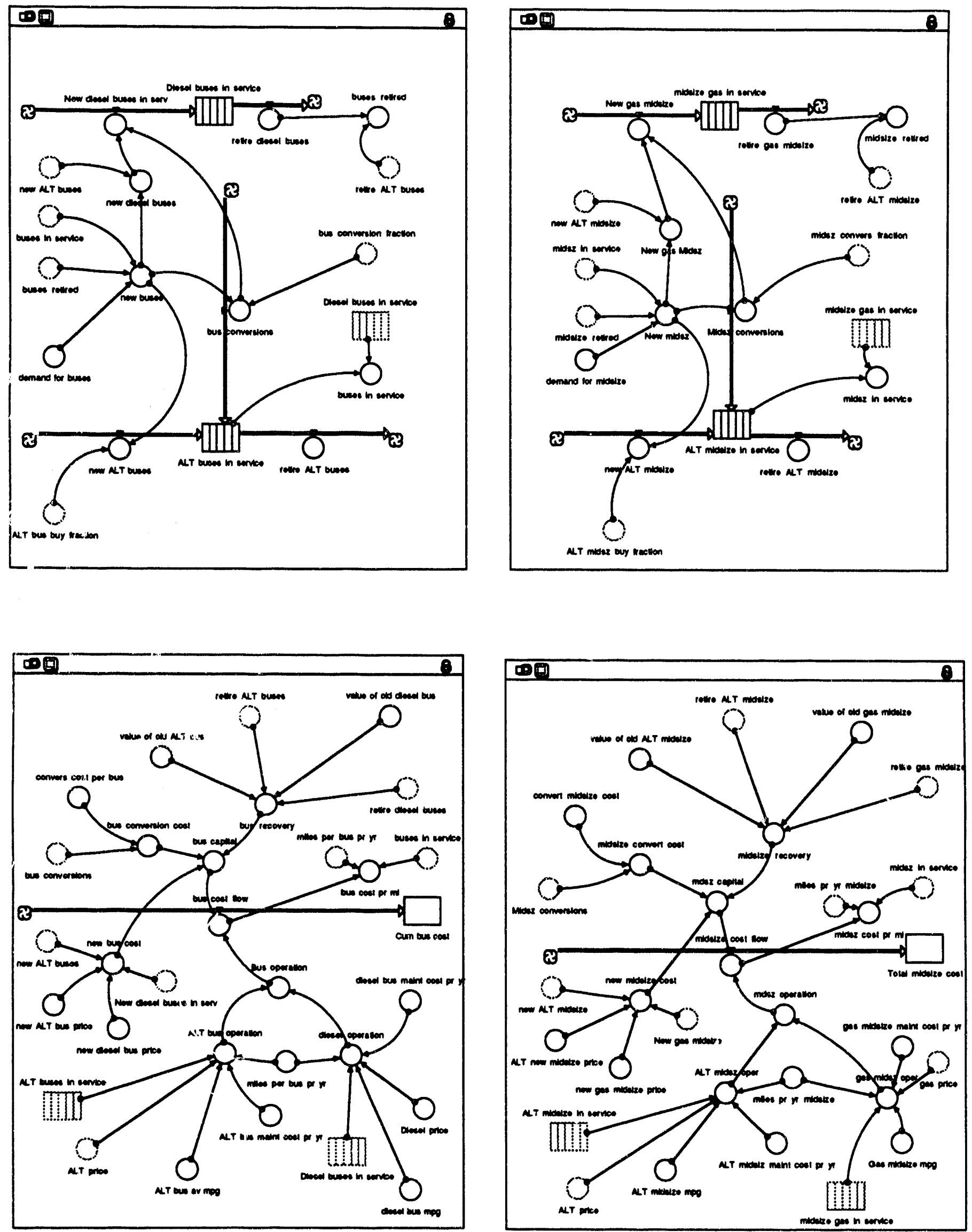

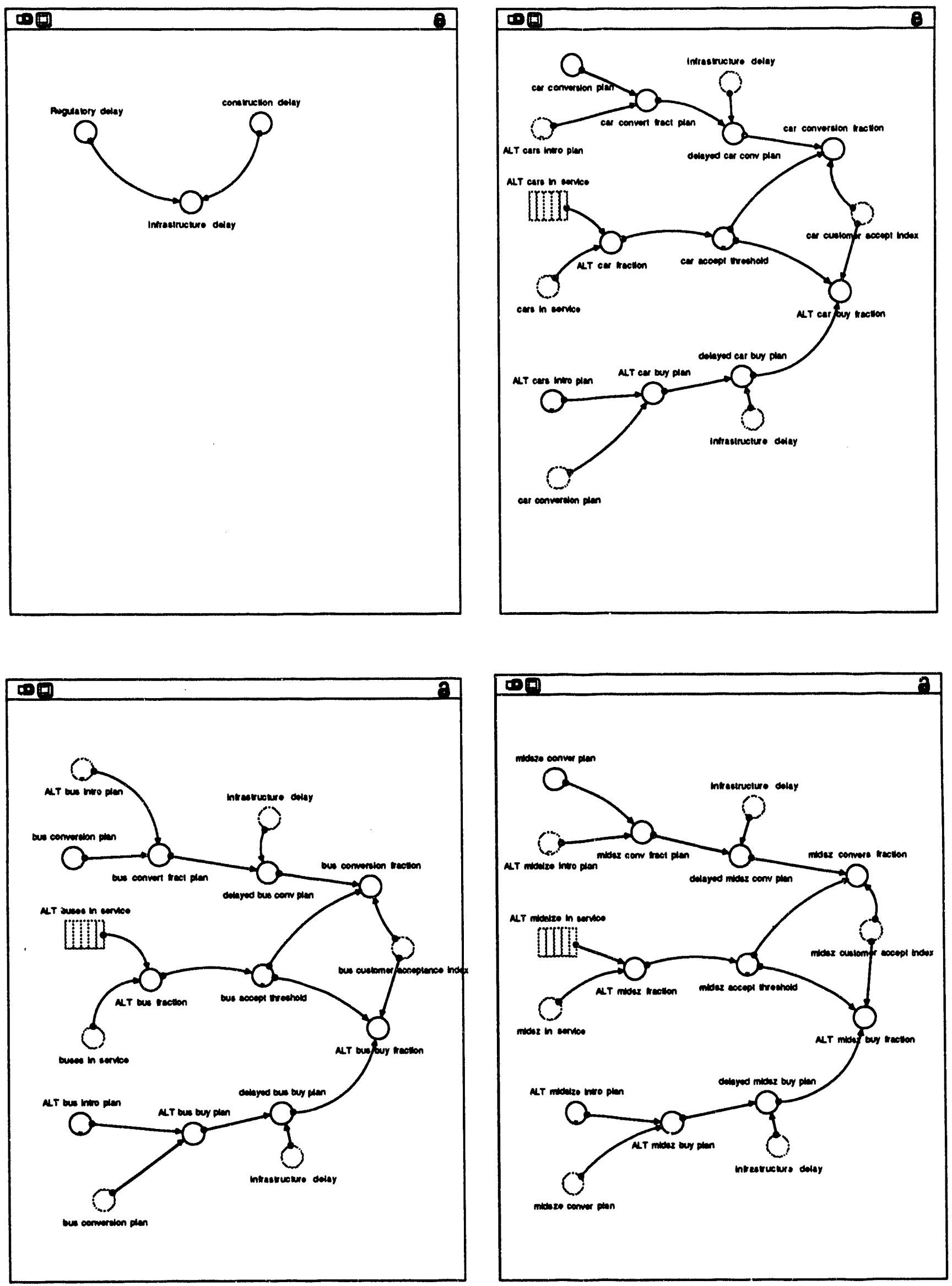

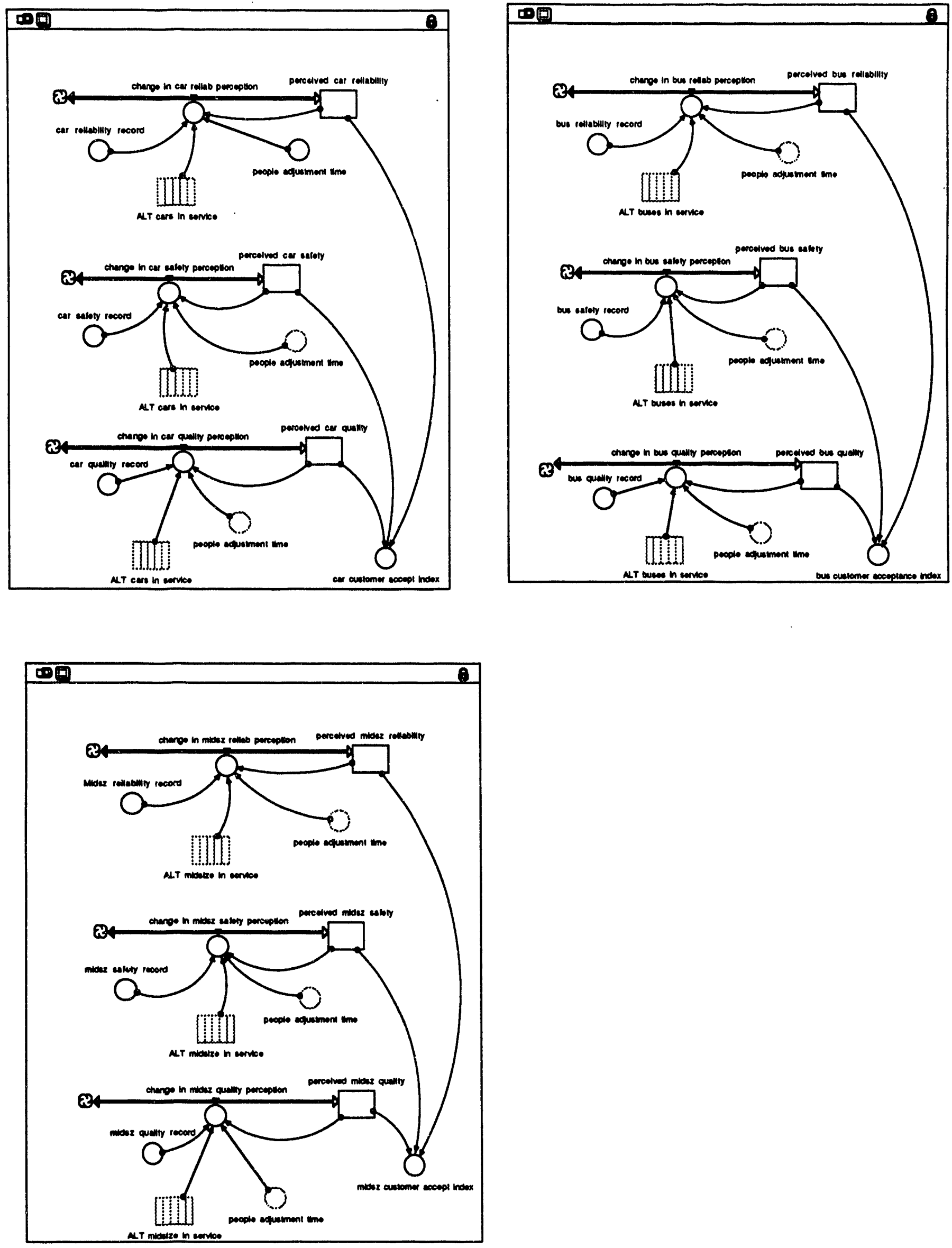
ALT bus Cuatomer eeceptenoe

AL percoived_bus_quality $(t)=$ percoived_bus_quallty $(t-d t)+($ change_in_bus_quality_percoption) $-d t$

NIT porcoivod_bus_quality $=1$

INFLWS:

*o change_in_bus_quality_percoption $=\mid F(A L T$ buses_in_sorvice $=0)$ THEN $(0)$

- parcoivod_bus_roliability $(t)=$ percolved_bus_foliabtity (t - dt) + (change_in_bus_rollab_percaption) - dt INIT porcoivod_bus_._retiablity =

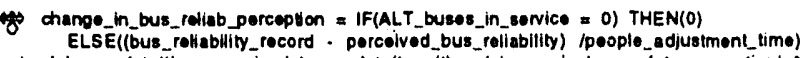

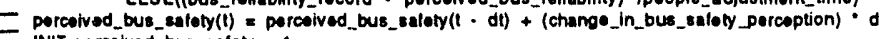
INIT percoived_buc_astoty = WFLOWS:

Honge_in_bus_saloty_percoption = IF(ALT_buses_tn_sorvice $=0$ ) THEN(0)

bus_customer_accoptanco_Index = (porceived_bus_quality+porcolved_bus_saloty+porcelved_bus_rollablity)/3

O bus_quality_rocord = 1

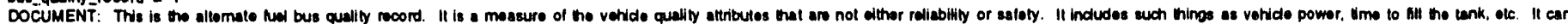

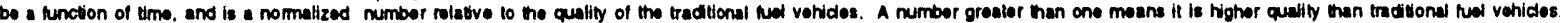

O bus_roliebility_rocord = 1

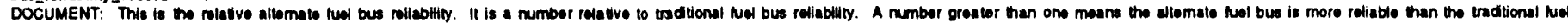

O bus_saloty_rocord $=1$

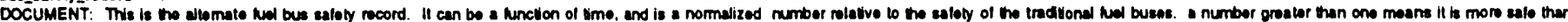
traditional thel buses.

ALT oar Cuatomor aceopteneo

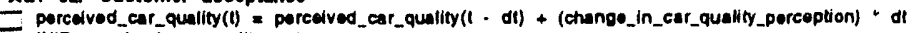
INIT percolved_car_quality $=1$

INFLOWS:

of chango_in_car_quatily_porcoption = IF(ALT_care_in_cervice >0) THEN(Car_quallity_rocord . porcolvod_car_quality) pooplo_odjustment_umo)

$$
\text { ELSE(0) }
$$

[ porcoived_car_raliability(t) = perceived_car_rollability(t - dt) + (chango_in_car_roliab_percoption) - dt INIT porcoived_car_rethabilly =

INROWN:

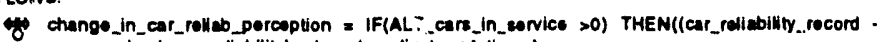
ELSE(0)

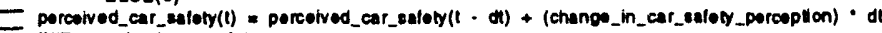
INIT percoived_car_entely $=1$

of chango_In_car_salory_poreoption = IF(ALT_cars_in_wovico >0) THEN((cat_saloty_record perceived_car_aloty Ypeople_adjustmoni_umo) ELSE(0)

O car_customer_accopt_index = (percoived_car_quality +porcoived_car_saloty tporcoivod_car_rotiabillty) 13

O car_quaility_record = 1

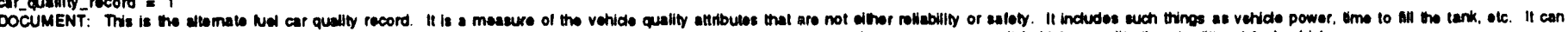

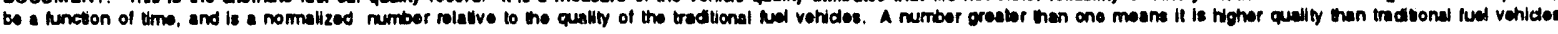

O car_rolisbility_tecord $=$

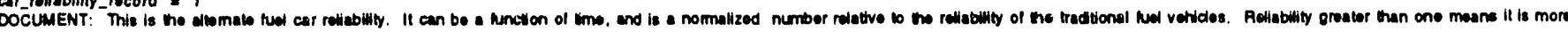

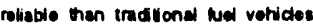

O car_eatery_recond $: 1$

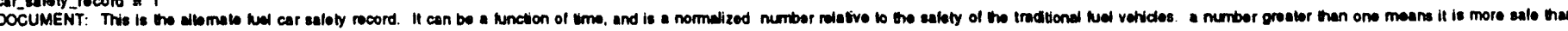
traditiona nel vohides.

O peoplo_adjustmont_timo $* 3$

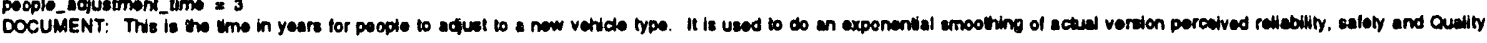

ALT midake vohlelo Cuatomer eecopteneo

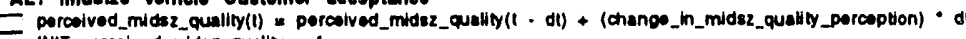

INIT percoived_midez_quality $=$

NFLOWs:

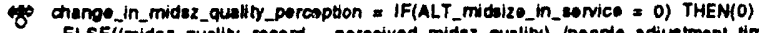

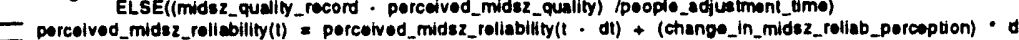

INIT porcotvod_midez_roliability =

NRLOWS:

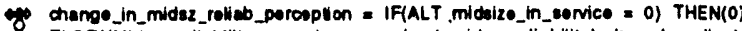

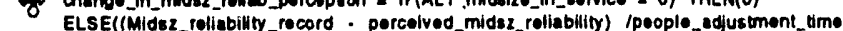

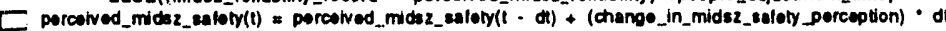

INIT percoived_midsz_entoly = 1

WFLOWS:

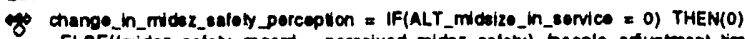

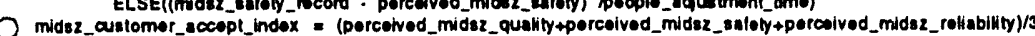

$\bigcirc$ midsz_quality_rocord =

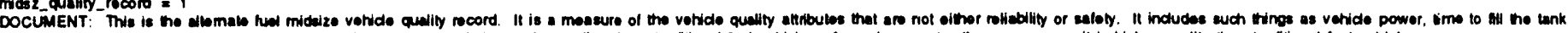

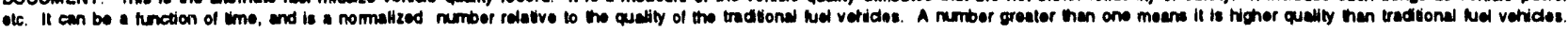

Midaz_reliablitity_rocord $=$

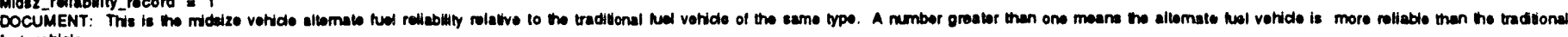
Neal vericlo.

Ordez_malety_rocord $=1$

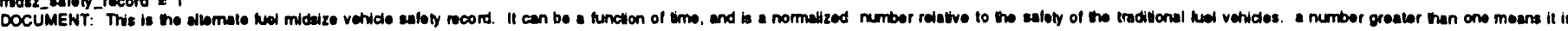
more sale than tredisonal thel veridos.

ALT fual oer introduction proceces

OALT_car_buy_Inction = IF(car_austomor_occopt_index) >x car_accopt_torounold THEN ALT_car_b
(delay
ELSE(0)
ALT_car_b

ELSE(0)

$O$ ALT_car_bly_plen = ALT_care_mitro_plen (1 -car_conversion_plen)

O ALT_car_traction = ALT_care_n_envico lears_in_sorvico

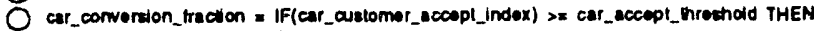
(dolayod_car_corw_dian)

ELSE(0) 
O car_convorsion_plan $=0$

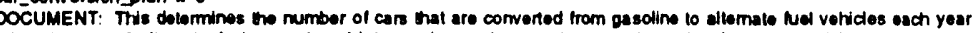

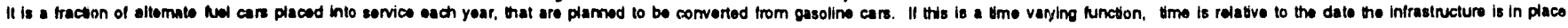

O car_conver_iract_plem = car_conversion_plan PALT_cars_Intro_plan

$O$ dolayed_car_bur_plan $=$ DELAY(ALT_car_buy_plan,inirastructure_dolay,0)

Oolayod_car_conv_plan $=$ DELAY(Car_convort_fract_plan,intrastructure_delay.0)

$\bigcirc$ ALT_cars_intro_plan $=$ GRAPH(TIME)

(1993, 0.1), (1004, 0.15), (1095, 0.2). (1996, 0.25). (1997, 0.33), (1998, 0.5), (1999, 0.67), (2000, 0.84), (2001, 1.00), (2002, 1.00), (2003, 1.00), (2004, 1.00), (2005, 1.00), (2006, 1.00), (2007, 1.00), (2006, 1.00), (2000. 1.00), (2010, 1.00), (2011, 1.00), (2012, 1.00), (2013, 1.00)

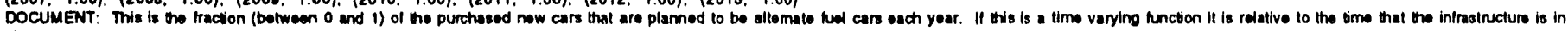

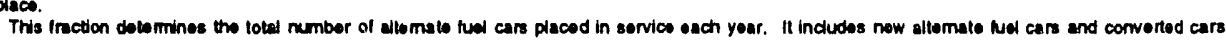

O car_accopt_throshold = GRAPH(ALT_car_traction)

$(0.00,0.5),(0.1,0.72),(0.2,0.9),(0.3,0.8),(0.4,0.8),(0.5,0.9),(0.6,0.9),(0.7,0.8),(0.8,0.9),(0.8,0.9),(1,0.8)$

ALT fuel bue intreduotion proecee

O ALT_bus_buy_traction = IF(bus_customer_acceptance_index) s= bus_accept_throshold THEN (delayed_bus_buy_pian)

ELSE(0)

O ALT_bue_bry_plan = ALT_bus_intro_plen '(1 - bus_convorsion_plan)

ALT_bus_fraction = ALT_buses_in_servico/buses_in_senvico

O (delayed_bu_coon_plan) ELSE(0)

$O$ bus_convoraion_plan $=0$

DOCUMENT: This dolomines the number of buses that are converted from diesel to ettomate tuel vohictes ench yoar.

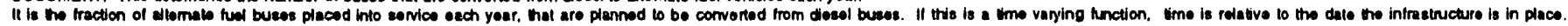

O bus_conver_lract_dlan = ALT_bus_Intro_plen "bus_converzion_plen

Odayod_bus_buy_plan $=$ DELAYYALTT_bus_buy_plan,ininstructure_dolay,0)

$O$ dolayed_bus_conv_plan $=$ DELAY(bus_convort_Iract_plan,inlrastructure_delay,0)

$\bigcirc$ ALT_bus_intro_pien = GRAPH(TIME)

(1903. 0.1), (1904, 0.15), (1095, 0.2), (1096, 0.25), (1097, 0.33), (1998, 0.5), (19009, 0.67), (2000, 0.84), (2001, 1.00), (2002, 1.00), (2003, 1.00), (2004, 1.00), (2005, 1.00), (2006, 1.00), (2007. 1.00), (2008, 1.00). (2000, 1.00). (2010, 1.00). (2011, 1.00), (2012, 1.00), (2013, 1.00)

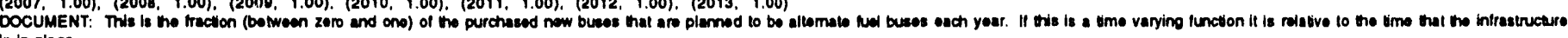
in in place.

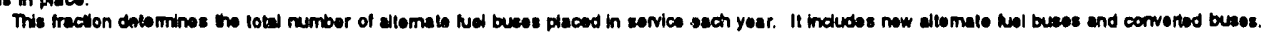

O bus_acopt_throstiold = GRAPH(ALT_bus_traction)

$(0.00,0.5),(0.1,0.72),(0.2,0.0),(0.3,0.0),(0.4,0.0),(0.5,0.0),(0.6,0.9),(0.7,0.0),(0.8,0.0),(0.0,0.8),(1,0.0)$

ALT tuol midetzo intro procenes

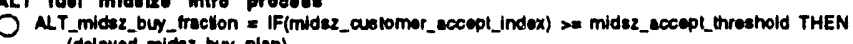
(delayed_midez_buy_plen) ELSE(0)

O ALT_midsz_buy_plan = ALT_midaizo_intro_plan * $(1$-mideze_convor_plan $)$

ALT_midsz_traction = ALT_midedzo_In_corvico /midsz_m_monico

Odolayed_midsz_buy_plan = DELAY(ALT_midaz_buy_plen,intrastructuro_dolay,0)

$O$ dolayod_midez_con_plan = DELAY(midsz_conv_Iract_plan,inirestrueture_delay,0)

midaze_convor_flen = 0

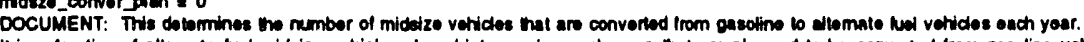

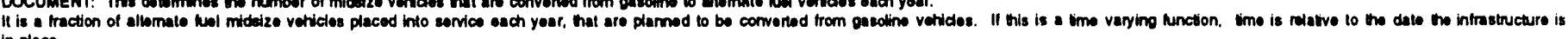
in placo.

O midsz_convors_traction $=\mid F($ midsz_ausiomor_acceplindex) $>$ midez_accopt_hreshold THEN (delayod_midsz_con__plan) ELSE(0)

midaz_conv_Iract_plen = mideze_convor_plan PALT_midelzo_mtro_plan

$O$ ALT_mideizo_intro_plen = GRAPH(TIME)

(1993, 0.1), (1994, 0.15), (1905, 0.2), (1896, 0.25), (1997, 0.33), (1098, 0.5), (1009, 0.67), (2000, 0.04), (2001, 1.00), (2002, 1.00), (2003, 1.00), (2004, 1.00), (2005, 1.00), (2000. 1.00), (2007, 1.00), (2000, 1.00). (2000, 1.00), (2010, 1.00), (2011, 1.00), (2012, 1.00), (2013, 1.00)

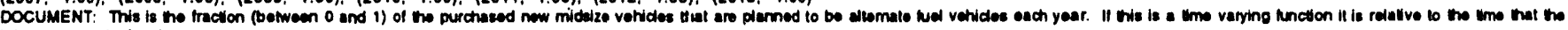
intrastructure is in place.

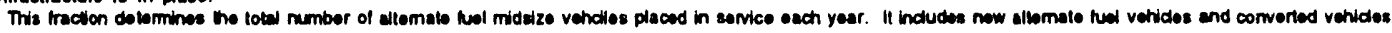

0 mosz_eccopt_throshold = GRAPH(ALT_midez_fraction)

$(0.00,0.5),(0.1,0.72),(0.2,0.0),(0.3,0.0),(0.4,0.9),(0.5,0.0),(0.8,0.0),(0.7,0.9),(0.8,0.9),(0.0,0.0),(1,0.9)$

Bus cost eneter

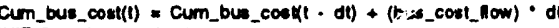
INIT Cum_bus_cosi $=0$

NFLOWS:

* bus_cost_how = bus_capited + Bus_operation

DOCUMENT: cost is in

ALT_bus_av_mpg = 5

for altomato hiel busee.

ALT_bun_maint_cost_pr_yr $=2500$

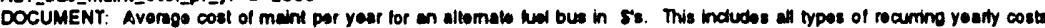

O ALT_bus_oporation = ALT_busos_In_sorvies.ALT_bus_maint_cost_pr_yr

+ ALT_busos_In_sorvico"(ALT_prica)"milos_por_bus_pr_yriaLT_bus_av_mpo

ous_capital = now_bue_cost tbus_convorsion_cost bus_rocovery

$\bigcirc$ bus_conversion_cont = convers_cost_per_bus'Bus_converitions

$\bigcirc$ but_cost_pr_mi = bue_cost_llow 1 (miles_per_bun_pr_yr * buses_m_sorvico)

O Bus_operation = ALT_bus_operation tolosel_operation

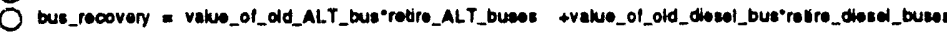

ocrwors_cost_por_wus = 35000

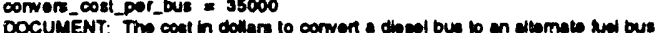

O dosel_bus_muint_cost_pr_yr $=4200$

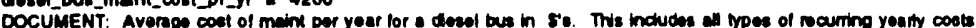

O deeci_bus_mog $=8$

DOCUMENT: Averape mileage in milles por gavion.

lor diecel bueps.

O desel_oporetion = Diesel_buses_in_cervice-diosol_bus_maint_cost_pr_yr

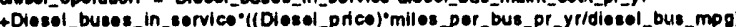


O Dlosal_price $=1.34$

DOCUMENT: prico of doeed hat in 8 por gallon.

$O$ milos_per_bus_pr_yr $=42000$

DOCUMENT: Avorage number of milos buess travel per year

Onow_ALT_bus_price $=300000$

DOCUMENT: Prico of a now altomato hol bus in S's.

$O$ now_bus_cost $=$ new_ALT_buses'new_ALT_bus_price + now_dosel_bus_prico'Now_diosel_busos_in_son

Onow_diesel_bus_price $=225000$

DOCUMENT: Price of a new doed bus in $\mathrm{se}$.

O value_d_dd_AlT_bus $=10000$

DOCUMENT: The averege price in dothan recolvod lor old mitred Altemato fual buses.

$O$ value_of_old_diead_bus $* 10000$

DOCUMENT: The average price in dotan recalved for old rollned dosew busere.

Dus coetor

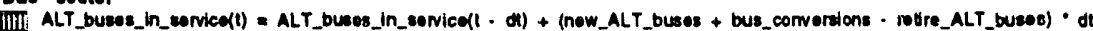

NIT ALT_busen_h_eorvice $=0$

TruNG

ENTLWNS:

Fo now_ALT_bustes = ALT_bus_buy_traction "now_buses

tous_convertion * bus_converdion_tracion inow_buses Oumpows:

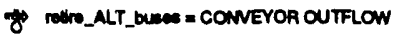

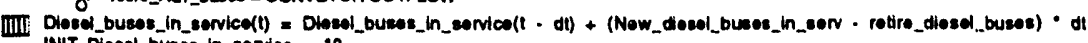

INIT Diosed_bües_n_entice = 10

TRANSIT TIME $=13$

ENTPANCE CAPACTYY $=1000$

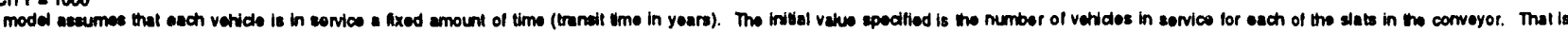

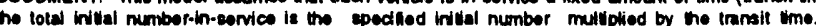

Mrows:

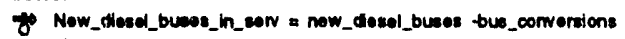

arrows:

* Nolro_dom_buem a CONVYYOR OUTFLOW

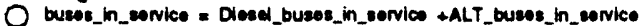

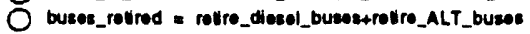

demand_for_bueses $=130$

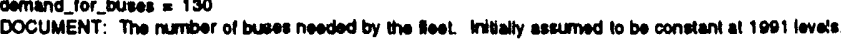

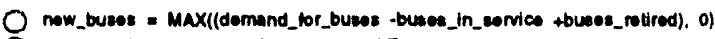

$\bigcirc$ new_diosel_buess = now_buecs -new_ALT_buses

Cer coel eoctor

Cum_car_cost $(t)=$ cum_car_costt $-d t)+\left(\cos r_{-} \cos i_{-}(n) w\right) \cdot d t$

INIT Cum_car_cost = 0

WRows:

* car_cost_now = car_capilal tear_oporation

ALT_ear_muint cost or_yr $=120$

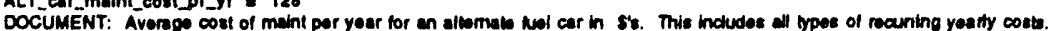

O ALT_Car_mog $\approx 27$

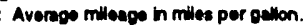

for altomalo hal cars.

O ALT_car_oporation = ALT_care_in_service*ALT_car_maint_cost_pr_yr

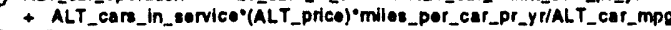

ALT_now_car_price $=14000$

DOCUMENT: Price of a now albmalo nol car in s's.

O ALT PRICE $=.62$

DOCUMENT: price of the allomate Red in s per equivelent gattion (equivalont 10

a gatton of gasoline in wims of oneroy)

O car_capital = car_conversion_cost thew_car_cost -car_rocovory

O car_corworsion_cost = convere_coat_per_car car_converaions

$\bigcirc$ car_cost_pr_mi $=$ car_cost_how / (milos_per_car_pr_yr - cars_in_sorvico)

$O$ car_operation = ALT_car_oporntion +oses_car_oper

car_rocovery = velue_ol_old_ALT_carrotiro_ALT_cars tvalue_ol_old_gas_carrotire_gas_can

convern_cost_per_car $=1500$

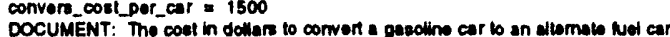

O pas_car_maint_cost_pr_yr $=162$

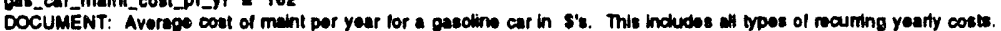

$O$ Gas car mos $=30$

DOCUMENT: Avernge mikage in miles per gellon.

lur geeolino cans.

O gas_car_opor = Gesollino_carn_In_ecrvico"gas_car_maint_cost_pr_yr

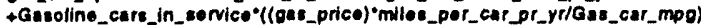

gas_prico = 1.103

DOCUMENT: pHico of gasedine in 8 per gallon.

milos_per_car_or_yr $=17300$

DOCUMENT: Avorage number of miles car travels por yoar

O now_car_cout = now_ALT_care'ALT_now_car_prico + now_gas_car_prico'Now_gas_cers

now_gas_car_prios $=9000$

DOCIUMENT: PAtco of a new ancoline car in 58

value_ol_old_ALT_car $=500$

DOCUMENT: The averege price in dollare necived for old notrod Altomato huel cems. 
$O$ value_ol_old_oes_car $=1000$

DOCUMENT: The average price in doltan mocived for old retred gasolime cars.

care ceotor

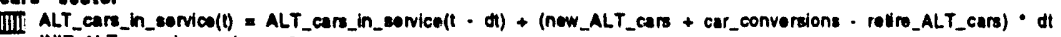

INIT ALT_Cars_in_envice $=0$

TRANSIT TIME $=7$

ENTPANCE CAPACITY $=0$

Writows:

\# now_ALT_cars = Now_cars alt_car_buy_Imction

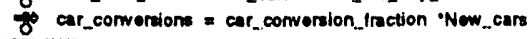

antrows

* MIN_ALT_CAE = CONVEYOR OUTFLOW

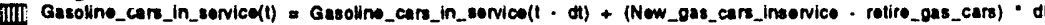

INIT Gasolino_carn_In_enNico = 22

TRANSIT TIME $=7$

ENTPANCE CAPACTT $=1000$

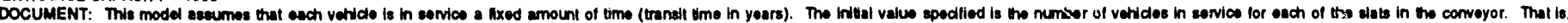

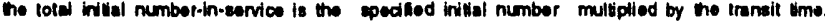

Whows:

to Now_ges_care_mervico = Now_gas_cars ccar_convervione

almows:

* Nire_as_can a CONVEYOA OUTFLOW

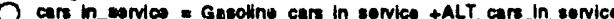

O care_roticod = rotire_gas_care+rotine_ALT_care

$O$ domend_for_caro $* 154$

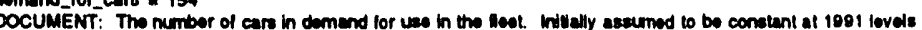

O Now_can = max( (demand_tor_cane cean_in_sonice +cars_rotired), 0$)$

O Now_one_care = Now_care - now_ALT_care

CO2 Emleclons

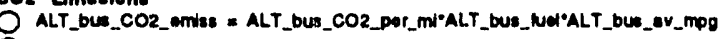

O ALT_bue_CO2_por_mi $=34.5$

DOCUMENT: Cation Dioxide misedione in grams por mile.

For ditemats ham buene.

O ALT_car_CO2_emles $=$ ALT_car_hol_how'ALT_car_CO2_por_mi-ALT_car_mpo

O ALT_car_CO2_per_m $=3.4$

DOCUMENT: Carion Dioxtde emideions in grams per mile.

For ellomilo hul cans.

ALT_CO2_emiedione = ALT_Car_CO2_emies + ALT_bus_CO2_omise +ALT_midez_CO2_emise

ALT_midez_CO2_omies $=$ aLT_mideizo_mpg'ALT_midez_CO2_pr_mi'ALT_mideize_hul_How

O ALT_midez_CO2_Pr_m $=4.4$

DOCUMENT: Carton Dloxido emiations in grems por milo.

For diemato vel mideize vohides.

O Olosel_bus__CO2_por_mi $=1.2$

DOCUMENT: Carbon Dioxide emindons in greme per mile. For desed buesen.

O Dlesel_CO2_omies = Diecel_bus_CO2_por_mi'Olesol_llow'dlesel_bus_mpo

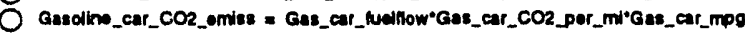

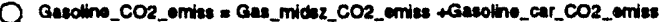

O Ges_car_co2_per_mi $=1.7$

DOCUMENT: Cation Dioxide emindions in areme per milo.

For giecoline carn.

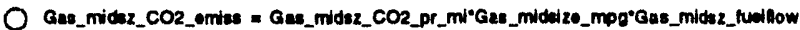

$\bigcirc$ Gas_midaz_CO2_pr $m$ mi $=.2$

DOCUMENT: Cartoon Dloxdes amidions in orams por mite.

For geseline middzo velictes.

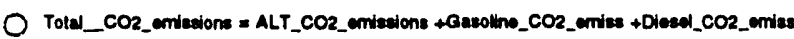

Fuele coeter

Document:

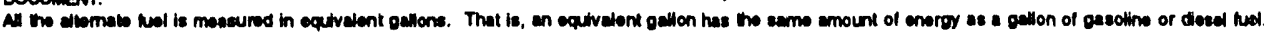

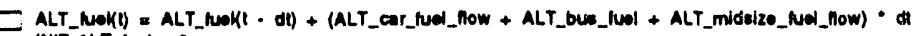

INIT ALT_NDI = 0

wrows:

7 ALT_car_tual_fiow $=$ ALT_can_in_sorvico'milos_por_car_pr_yr/ALT_car_mpg

- ALT_bus_tual = ALT_busos_in_oorvico"mllos_per_bus_pr_yr/ALT_bus_av_mpo

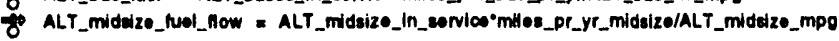

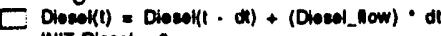

WIT Divel = 0

WROWS:

7Dlosel_now = Diesel_buses_In_sorvice"miles_per_bus_pr_yr/diesol_bus_mpg

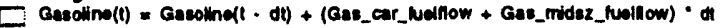

INIT Gasolinio = 0

MNIT Gaws:

* Gas_car_tuolthow = Gasoline_can_in_sorvice miles_por_car_pr_yr/Gas_car_mpo

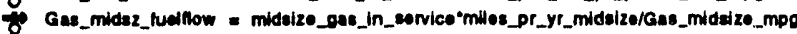

Midetize vehlore coot esotor

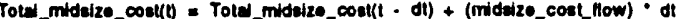

NIT Total midele coet $=0$

Wincows:

of midaize_coet_llow = molez_capital +matez_oporation

DOCUMENT: costis in 8 .

OAt_mideize_mog $=10$

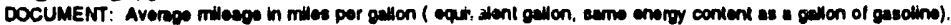

for allomalo huel midesize vechicios. 
OALT_midsiz_maint_cost_pr_yr $=120$

DOCUMENT: Avorago cost of maint por year for an altomate hool mideize vetide in S's. This indudes all typos of recurring yoarty costs.

O ALT_midsz_oper = ALT_midsize_in_sowico'ALT_midsiz_maint_cost_pr_yr

+ ALT_midaize_in_sorvico'(ALT_Price) ${ }^{\circ}$ miles_Pr_yr_midalzo/ALT_midsize_mpg

O ALT_now_midaize_price = 14000

COCUMENT: PHce of a new allomato hal midsize vehide in S's.

$O$ convert_midaize_cost $=2000$

DOCUMENT: the cost in dollers to convert a gesoline mideize vetide to an altermato hul vohide.

0 gas_midaize_maint_cost_pr_yr $=200$

DOCUAENT: Avorage cost of maint per yoar for a pasoline midsize votide in S's. This indudes all types of reauring yosity costs.

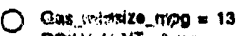

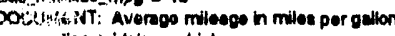

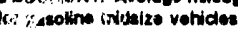

O gan_midez_cper = midaizo_par_In_conico'ous_midrizo_maint_cost_pr_yr

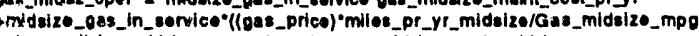

motuz_capitel = midsize_convert_cost + now_mideize_cost -midaize_tocovery

O mokz_cperation = ALT_midaz_oper +pas_midex_opor

O midaize_convert_coul = convert_midaize_costrMidsz_convoreions

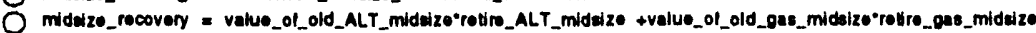

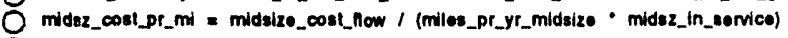

Oilos_pr_yr_midaize $=10700$

DOCUMENT: Avernge number of milles midelze vehides travel per yoar

now_gas_midaizo_price $=12000$

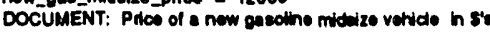

O now_midaize_cost $=$ now_ALT_mideizo'ALT_now_mideize_price + now_gas_midelze_prico'Now_gas_mideizo

$O$ valus_ol_old_ALT_midaize $=500$

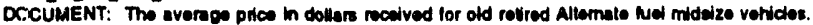

O value_of_old_ous_midedze $=1000$

DOCUMENT: The avernes price in dollars recetved for old relired gasoline mideize vathides.

Mideke vohleles coetor

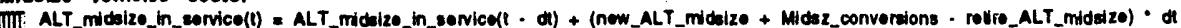

INIT ALT_imidaize_th_sorvice $=0$

TRANSIT TIME $=7$

ENTRUNCE CAPACITY = -

WFLOWS:

Fow_ALT_midelze = ALT_midez_buy_traction New_midez

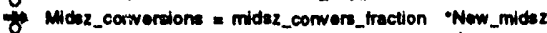
olfows:

* NHo_ALT_midizo = CONVEYOR OUTFLOW

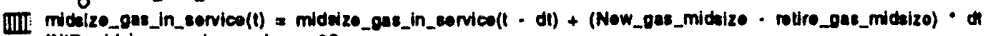

INIT midsize_gas_In_entilos $=05$

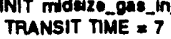

ENTPUNCE CAPACTTY $=1000$

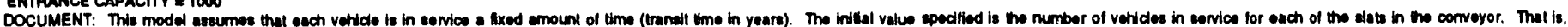

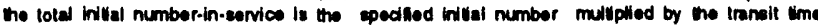

NFLOWS:

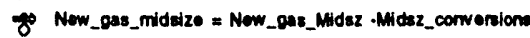

arifows:

* rolio_ans_mideizo = CONVYOR OUTFLOW

O domand_for_midaizo $=595$

DOCUMENT: The number of mideize vetides needed by the lleet. Aseurned to be comatent at 1001 loveds.

O midsizo_rotred = retire_gas_midalzotrotiro_ALT_mideize

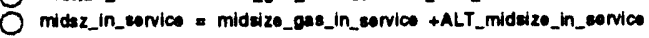

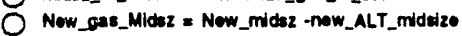

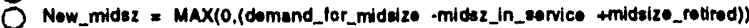

NMHC Einlealone

DOCUMENT:

This soctor calulates the total NMHC (Non-Mothens Hydro Carbons) emmisstons for the ontire Beol oach yoar.

ALT_bus_NMHC_emiss a ALT_bus_NMHC_por_mi ALT_bus_thal'ALLT_bus_av_mpo

$\bigcirc$ ALT_bus_NMHC_por_mi $=.5$

DOCUMENT: NonMeithene Hydro Catbon errisuions in grame per mile.

For altomato fuel buses.

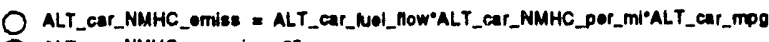

$\bigcirc$ ALT_car_NMHC_por_mi $=.25$

DOCUMENT: NonMathene Hydro Catoon emlasione in grame por mule. For atiomato thal cars.

O ALT_midsz_NMHC_omiss $=$ ALT_midsize_mpo'ALT_midzz_NMHC_pr_mi'ALT_midaizo_hNol_HOW

O ALT_midez_NMHC_pr_mi $=1.7$

DOCUMENT: NonNethene Hydro Catbon emiscions in greme por mits.

For allomato nal midestze votidos.

OLT_NMHC_omies = ALT_Car_NMHC_emise + ALT_bue_NMHC_omies +ALT_midez_NMHC_omines

$O$ Decel_bus_NMHC_per_mi $=1.7$

DOCUMENT: Non-Wothane Hyro Catbons entedione in orame por mito. For deed buest.

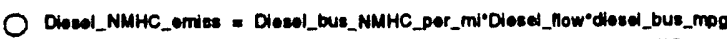

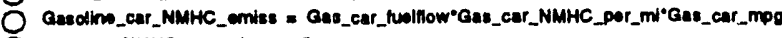

$O$ Ges_car_NMHC_per_mi $=.125$

DOCUMENT: Non-Motheno Hyro Catbons emisesione in greme por milo.

For geooline care.

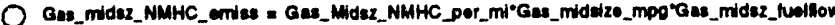

O Ges_Mudez_NMHC_per_ma $=.125$

DOCUMENT: Non-Methano Hyro Carbons emiestons in grame per mile.

For gaceline mideize veticlos. 


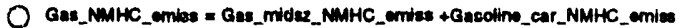

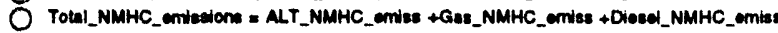

Mox Emiacione

O ALT_bus_NOX_cmiss = ALT_bue_NOX_por_mi'ALT_bus_NG1'ALIT_bus_ev_mpg

O ALT_bus_NOX__per_mi $=1.5$

DOCUMENT: Nitros Oxide compound emiseions in grame por mile. For attomato huel buses.

O ALT_Car_NOX_Omise = ALT_Car_hul_llow'ALT_car_NOX_por_mi-ALT_car_mpg

O ALT_car_NOX_por_ml $=.4$ DOCUMENT: Nitros Oxide compound entiestione in grame por mille. For altomat tuel cars.

O ALT_midez_NOX_omiee $=$ ALT_midelze_mpo'ALT_midez_NOX_Pt_mi'ALT_mideize_tual_how

O ALT_mides_NOX_Pr $m=.7$

DOCUMENT: NHos Oxibe compound exriselone in oreme per mile.

For ditemute kel midatze vetichss.

O ALT_NOX_emias = ALT_Car_NOX_emias +ALT_bus_NOX_emiss + ALT_midaz_NOX_emiss

O Dlezel_bus_NOX_per_mi $=1.2$

DOCUMENT: NHos Oxide compound emisedione in grems por mile.

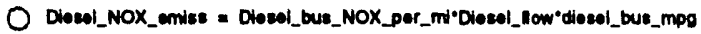

O Gasolline_car_NOX_cmise = Gas_car_hwolllow*Gas_car_NOX_por_mi"Gas_car_mpg

O Gas_car_NOX_per_mi $=.2$

DOCUMENT: Niltros Oxids compound milewiors in orams per mile. For gavolino cars.

O Ges_midez_NOX_omise = Ges_mider_NOX_per_mi-Ges_midaizo_mog"Gas_midn2_huelliow

O Ges_mider_NOX_per_mi = .2

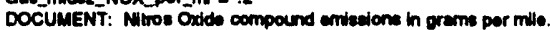

For gesolino midelize vahidos.

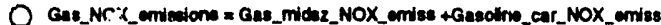

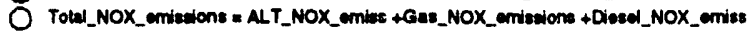

sleriup

Conativation_delay $=0$

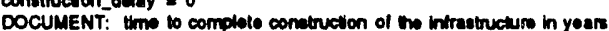

intrastructure_dolay = (Ropulabry_delay+conotruetion_doley)

Reoulatory_delay $=0$

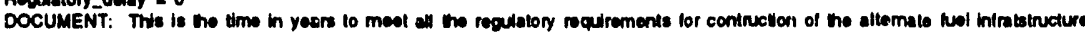

Totele

Camulative_cost $(t)=$ aumulative_cost $(t \cdot d t)+($ Coot_llow $) \cdot d t$

INTT amidelvo_coel =

WrLows:

* Cool_now $=$ Tolw_operation + Totw_capite

0 cost_of_Inirastructure $=500000$

DOCUMENT: Total cost of putting an intrastructuro in pleces (in dollare).

Cum_proeent_cost $=$ NPV(Cost_How,decount_rato.0)

DOCUMENT: Not Proment coat

0 decount_nto $=.08$

DOCUMENT: This be the tho velus of money decount nite

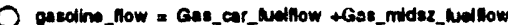

Oniranti_cost_Row = STEP(COAt_of_inirastructuro.inirastructure_dolay+STAATTIME)

-STEP(cost of inirastructure, inimatineture dolay+STARTTIME+1)

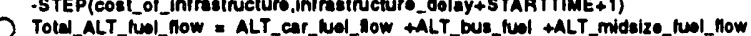

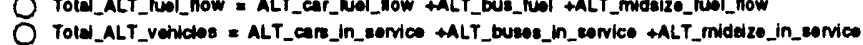

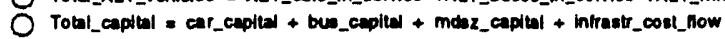

Total_convent__tuel_how = Diosel_llow + gasoline_low

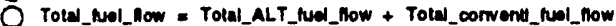

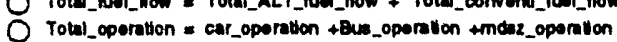

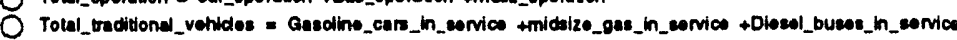

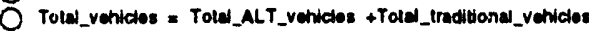


Appendix C

Input Data

C-1 
Table C-1 presents the input variables used in the I-think ${ }^{\mathrm{TM}}$ model used in the analysis. Where appropriate, values are given for each of the three vehicle types. The ranges represent the maximum and minimum values expected over the 20 years of the analysis. 


\section{REFERENCES}

1. World Oil Trends, Aurthur Andersen \& Co. and Cambridge Energy Research Associates, 1989-90 Edition

2. Comparison of New Federal Clean Air Act Amendments and California Low-emission Vehicle Rules, Implications of Air Quality Programs for Alternative Fuels, Acurex Corporation, February 5-7, 1991.

3. The Delpsi VI Forecast and Analysis of the U.S. Automotive Industry Through the Year 2000, Office for the Study of Automotive Transportation (OSTA), University of Michigan Transportation Research Institute, 1991

4. Second Interim Report of the Interagency Commission on Alternative Motor Fuels, September 1991

5. Natural Gas Vehicles, American Gas Association Newsletter, January/February 1992

6. Alternative Fuels Research Guidebook: Characterization, Instrumentation, Engine and Vehicle Testing, The Pennsylvania State University and National Institute for Petroleum and Energy Research, U.S. Department of Energy Report DOE/CE/50046-1, December 1985

7. R.W. Duncan, "Operating Experience of compressed Natural Gas Fueled Buses in Regular Transit Service," SAE Paper 892138, Society of Automotive Engineers, 1989

8. Liquefied Natural Gas Vehicle and Refueling System Analysis and Risk/Safety Assessment, Acurex Corporation, April 5, 1991

9. Ibid.

10. C.S. Weaver, "Natural Gas Vehicles - A Review of the State of the Art," SAE Paper 892133, Society of Automotive Engineers.

11. R.L. Bechtold, R.R. Tison, R.J. Sprafka, "The Practical and Economic Considerations of Converting Highway Vehicles to Use Natural Gas as Fuel," SAE Paper 831071, Society of Automotive Engineers.

12. Guidance on Estimating Motor Vehicle Emission Reductions from the Use of Alternative Fuels and Fuel Blends, U.S. Environmental Protection Agency, EPA-AA-AA-TSS-PS-87-4, January 29, 1988.

13. J. Stephenson, "Natural Gas Vehicle 1990," Auckland: International Association for Natural Gas Vehicles, 1990.

14. M. Nimox, "Liquefied Natural Gas For Fleet Vehicles an Industry Overview," Liquid Carbonic Industries Paper, 1991.

15. The Clean Fuels Report, J.E. Sinor Consultants, Inc., February 1992. 
16. Alternative Fuel Performance and Emission Characteristics, University of Miami, U.S. Department of Energy Report DOE/CS/50028-H1, January 1987.

17. Cost and Availability of Low-Emission Motor Vehicles and Fuels, AB234 Report Update, Draft, California Energy Commission, August 1992.

18. Optimized Methanol and Natural Gas Fueled Vehicles Toptech September 12-13, 1990 Knoxville, Tn., Continuing Professional Development Program, Warrendale, PA., Society of Automotive Engineers, Inc., 1991.

19. R.N. McGill and E.E. Ecklund, "Introducing Methanol-Fueled Vehicles Into Government Fleet Operations," presented at the VII International Symposium on Alcohol Fuels, Paris, France, October 1986.

20. V.R. Burns, Sr., "Chrysler's Flexible-Fuel and Gasoline Tolerant Methanol Vehicle Development," SAE Government/Industry Meeting, Warrenton, PA., Society of Automotive Engineers, Inc., 1989.

21. R.N. Nickols, S. Moulton, N. Sefer, and E.E. Ecklund, "Options for Introduction of Methanol as a Transportation Fuel," SAE Paper 861593, Society of Automotive Engineers, October 1986.

22. "Planning and Analysis Issues", The American Gas Association Newsletter, Issue Brief 1990-3, January 11, 1990.

23. "Planning and Analysis Issues", The American Gas Association Newsletter, Issue Brief 1992-3, March 20, 1992

24. "Planning and analysis Issues", The American Gas Association Newsletter, Issue Brief 1991-9, July 3, 1991

25. G. Brusagline, "Electric Vehicle Development in Fiat," SAE Paper 910244, Warrenton, PA., Society of Automotive Engineers, 1991.

26. Senge, Peter M., The Fifth Discipline, Doubleday, Augus: 1990.

27. High Performance Systems Inc., I-think ${ }^{\text {MN }}$ User's Guide, 1991. 


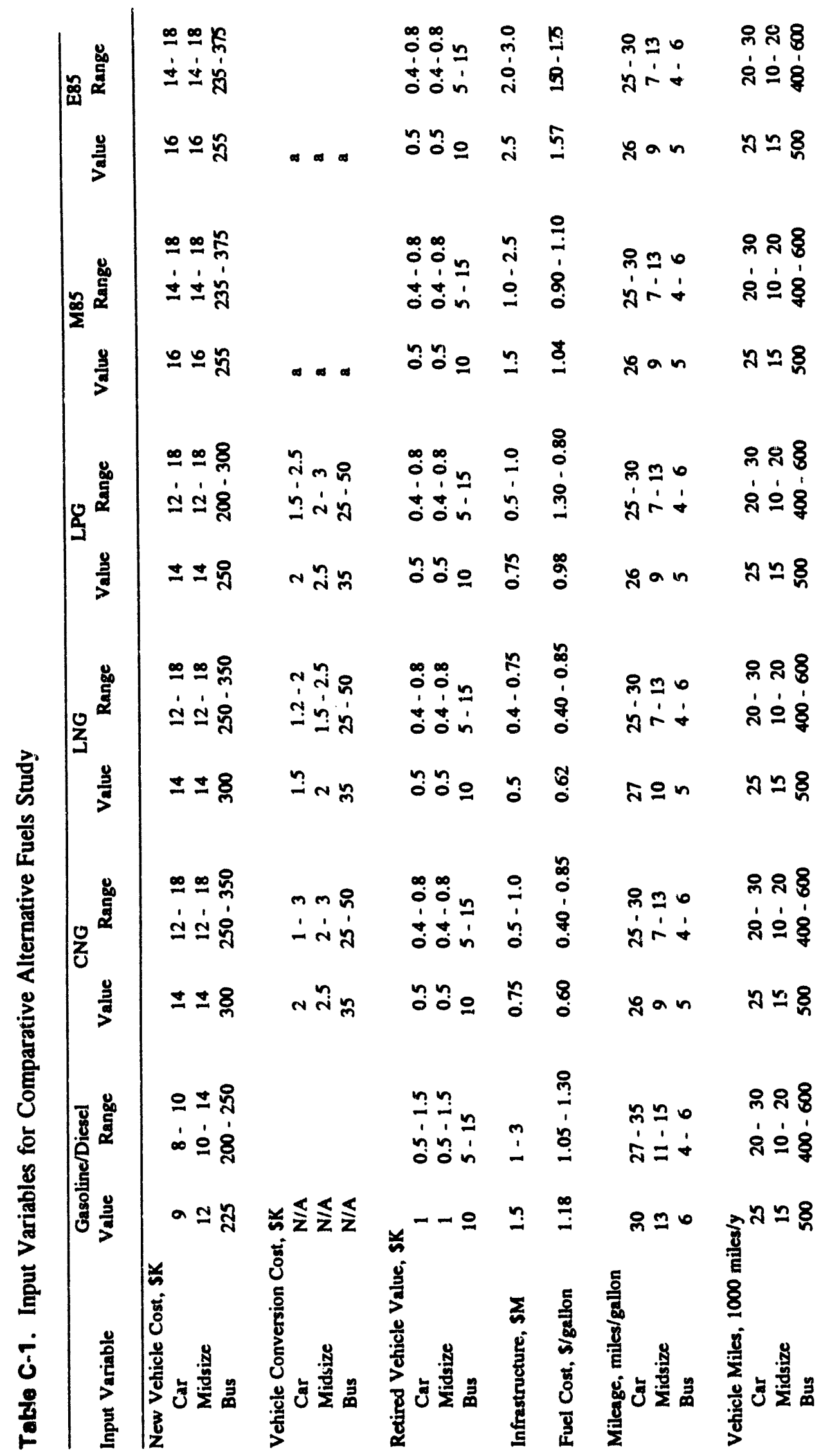




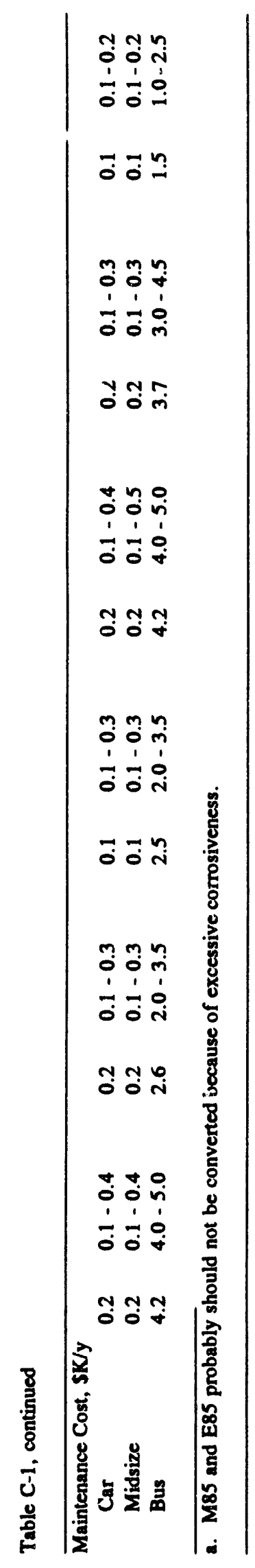



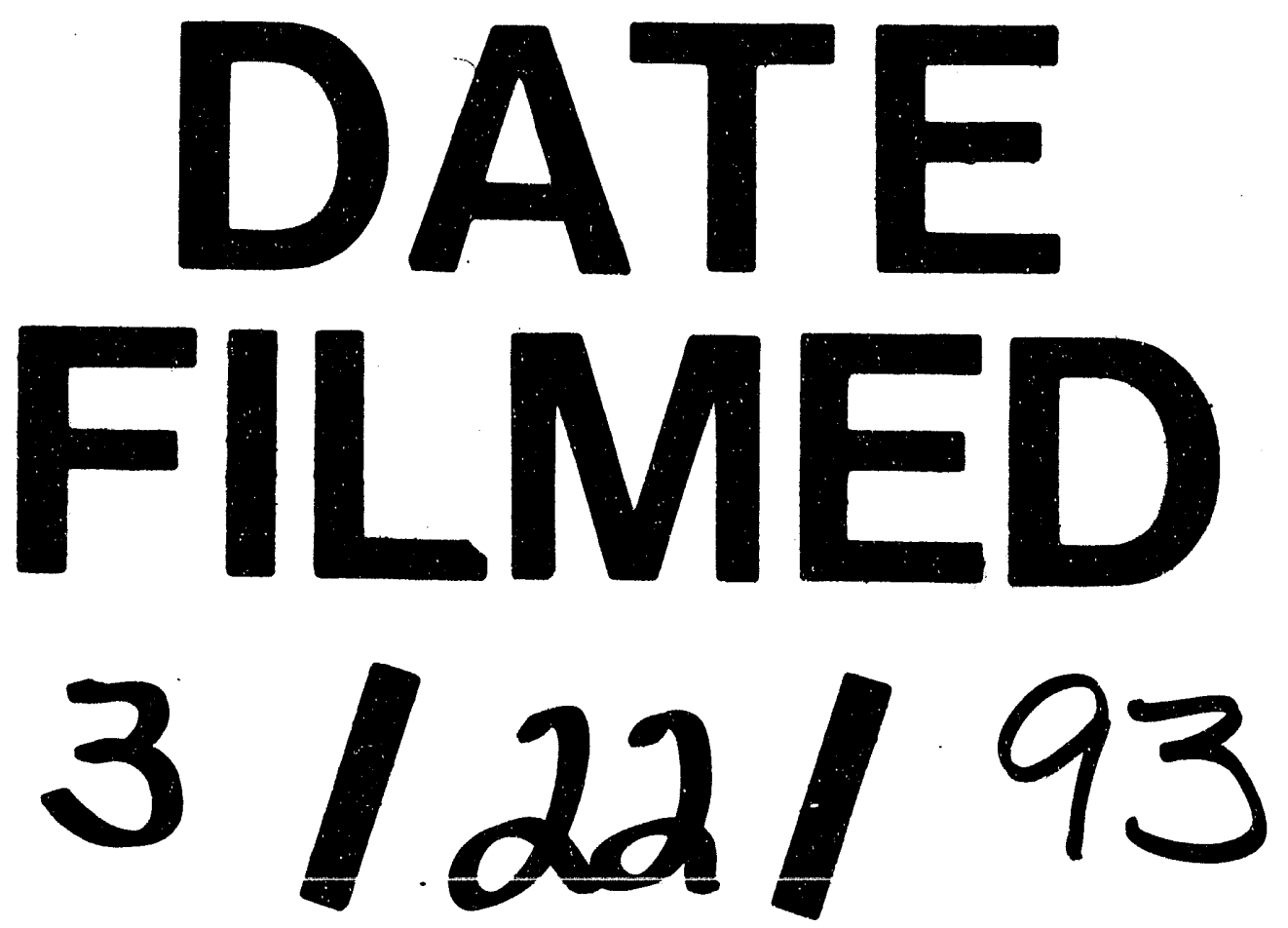
